Article

\title{
The Effect of Temperature and Time of the Hydrothermal Treatment in the SBA-15 Synthesis Process on the Structure and Textural Properties and the Ability to Reduce the Evolution of Tars in Tobacco Smoking
}

\author{
Nerea Juárez-Serrano ${ }^{\mathbb{D}}$, Javier Asensio, Isabel Martínez-Castellanos, Maribel Beltrán and \\ Antonio Marcilla * \\ Chemical Engineering Department, University of Alicante, Apartado 99, 03690 Alicante, Spain; \\ nerea.juarez@ua.es (N.J.-S.); javier.asensio@ua.es (J.A.); i.martinez@ua.es (I.M.-C.); maribel.beltran@ua.es (M.B.) \\ * Correspondence: antonio.marcilla@ua.es
}

Received: 9 February 2020; Accepted: 26 February 2020; Published: 1 March 2020

\begin{abstract}
Different SBA-15 (SBA, Santa Barbara Amorphous) materials were synthetized at different temperature and time during of the hydrothermal treatment. The obtained SBA-15 were characterized by $\mathrm{N}_{2}$ adsorption isotherms, scanning electron microscopy (SEM), X-ray diffraction (DRX), and density in order to establish the influence of these variables on their properties. Mixtures of the obtained catalysts with 3R4F tobacco were prepared and smoked under the ISO 3308 conditions. Temperature of the hydrothermal treatment slightly affects the tars that evolved in the smoking process of the corresponding catalyst tobacco mixtures. Contrarily, the time of the hydrothermal treatment has a marked effect on the reductions of toxic compounds in the smoke. Developed porosity has a positive correlation with the observed tar reduction, whereas the apparent density has a negative correlation with the reduction in toxicity. Moreover, the removal of the supernatant liquors during the hydrothermal treatment does not strongly modify the properties of the materials and may represent an interesting simplification of the process.
\end{abstract}

Keywords: SBA-15; hydrothermal treatment $(\mathrm{H})$, tobacco additive; tobacco toxicity reduction; smoke composition; $\mathrm{H}$ temperature; hydrothermal condition optimization

\section{Introduction}

A large amount of studies focused on determining the effect of tobacco on human health. Since before the 1980s, it has been known that the habit of consuming tobacco is the main cause of lung and oral cancer [1,2]. Tobacco smoke exposure also produces harmful effects to non-smokers [3,4]. From the confirmation of these new revelations, the need arose to prevent and control this deeply ingrained habit. However, until the last few decades, no great efforts had been made to reduce the consumption of tobacco through campaigns of awareness about the effects of smoking on health, increasing costs, or prohibiting consumption in certain places [5-7]. In this respect, although the percentage of the smoking population has been reduced, many people still consume tobacco.

Finally, and as a result of the great difficulty of completely eradicating tobacco consumption, efforts have been made to investigate the addition of different materials to reduce the number of toxic compounds in tobacco smoke. In this sense, some zeolites have been studied as elements capable of retaining some of these compounds [8-11]. Marcilla et al. [12] investigated the effect of three porous materials-HUSY, NaY, and Al-MCM-41-on the smoke composition of 10 commercial cigarette 
brands. Al-MCM-41 presented the best reduction percentages of toxic compounds, followed by HUSY, and finally NaY. Wu et al. [13] analysed the effect of ZSM-5 and NaY. Due to the larger pore size and pore volume, NaY could adsorb and decompose more nitrosamines than NaZSM-5. Moreover, they observed that zeolites with proton or sodium cation form acid zeolites and exhibit a higher activity to decompose nitrosamines than their basic analogues.

SBA-15 is a mesoporous material that has also been studied as a tobacco additive, yielding high reductions of toxic compounds. In a previous work, Marcilla et al. [9] analyzed the effect of the concentration of SBA-15 added to tobacco cigarettes on its catalytic effect on the composition of the smoke. They observed high reduction levels at the different concentration of SBA-15 studied.

Generally, the synthesis process of SBA-15 takes place through the following four principal steps: pre-treatment, hydrothermal treatment, drying, and calcination. In the bibliography, many studies can be found on the influence of the synthesis conditions on the properties of the material-mainly the first and second steps (i.e., references [14-19]).

Many authors have studied the interactions of the surfactant with the silica prior to the calcination step (for instance, references [20,21]). Studies developed by Kleitz et al. [22] and Bérubé and Kaliaguine [23], revealed that the P123 is removed at different temperatures depending on the atmosphere, i.e., at much lower temperatures in the presence of oxygen. The silica structure seems to catalyze the decomposition of the copolymer under air atmosphere. On the other hand, the P123 is oxidized depending on the position in the SBA-15 structure, i.e., a structure occupying the mesopores is oxidized at lower temperatures than that at the intrawall micropores.

The hydrothermal treatment has a marked influence on the texture developed by SBA-15 materials [24]. Fulvio et al. [25] showed the effect of time and temperature of the hydrothermal treatment using two silica sources (tetraethyl orthosilicate (TEOS) and sodium metasilicate). They found a decrease in surface area when increasing time and temperature of the hydrothermal treatment. In addition, mesopore volume and diameter showed an increasing tendency. Other authors have also reported similar results (for instance, references [20,26,27]).

The textural properties of the catalysts are likely to affect its behavior in every particular application. Nevertheless, when studying the effect of SBA-15 on the reduction of toxicants in tobacco smoke only a single material has been studied. We have not found any studies on the effect of the different properties and textures of SBA-15 materials on the catalytic effect for tobacco smoke toxicants reduction. On another hand, there are no commercial availability of SBA-15 of different textural properties. Consequently, if such a study is to be developed, the corresponding samples must be "ad hoc" synthetized. Thus, the main objective of the present work is to analyze the influence of the time and temperature of the hydrothermal treatment during the synthesis of the SBA-15, using TEOS as the silica source on the texture of the SBA-15 obtained as well as using such samples for studying the influence of their properties on the emission of toxic compounds when smoking their mixtures with 3R4F reference tobacco. Additionally, hydrothermal treatment is generally described as being carried out on autoclaves or tapered vessels. This fact may have a large influence on the cost of the equipment when trying to manufacture large amounts of this type of material for industrial applications, since large-volume reactors capable of standing the developed pressures would be required. In this sense, another objective of this work is to study the effect of removing the supernatant liquid before the hydrothermal treatment, thus dramatically reducing the required volume of the hydrothermal reactors. Both objectives would contribute to optimizing and simplifying the SBA-15 synthesis conditions for this tobacco application.

\section{Results and Discussion}

\subsection{Synthesis of SBA-15}

Figures 1 and 2 present the X-ray diffraction (XRD) patterns of the synthesized SBA-15. The results show the three typical peaks corresponding to the diffraction planes—(100), (110), and (200)—of 
the SBA-15. This pattern is characteristic of the ordered structure of the 2D hexagonal space group $(p 6 m m)$ [28].

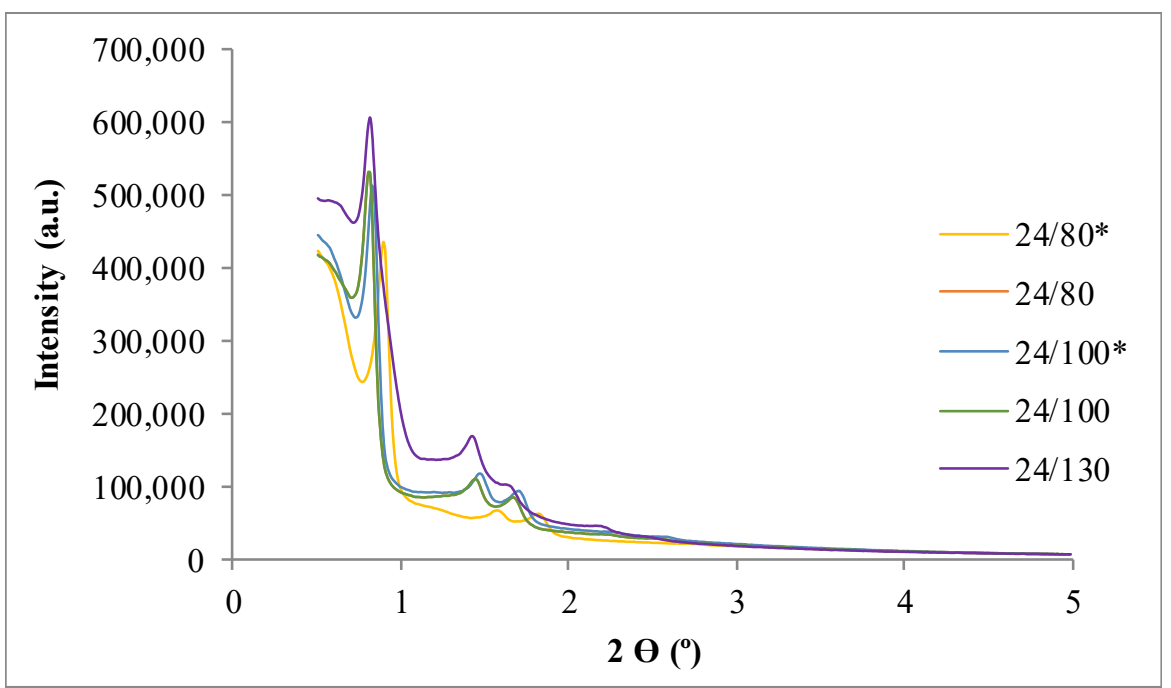

Figure 1. Low angle X-ray diffraction (XRD) patterns of samples for the study of the influence of temperatures $(\mathrm{TH})$ and the effect of reduction of supernatant liquor. ${ }^{*}$ Synthesis developed without reducing the supernatant liquor before the hydrothermal treatment.

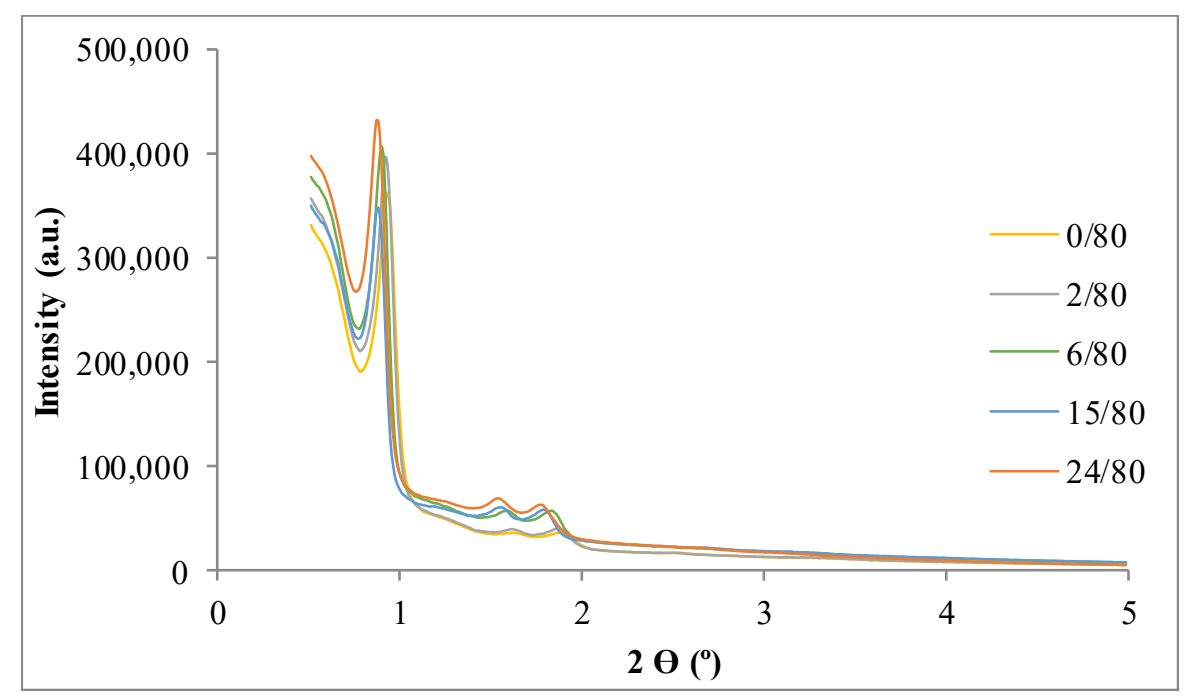

Figure 2. Low angle X-ray diffraction patterns of samples for the study of the influence of time (tH).

The unit cell parameter [29], together with the other textural parameters, are shown in Table 1. Table 1 also shows an estimation of the relative energy required (RER) for each synthesis with respect to the 24/100* synthesis RER, considering that to obtain $1 \mathrm{~g}$ of material the reaction mass is around 72 $\mathrm{g}$ ( $24 \mathrm{~g}$ for samples after reducing the excess supernatant medium), the temperature and time of the reaction and hydrothermal treatment, and the energy required to heat the sample (heat losses can be considered similar for all experiments). Significant energy savings can be obtained for all samples by reducing the supernatant and obtaining excellent catalyst performance for most of the samples. Another aspect that further contribute to the economy of the process is the possibility of working a low temperature as $80^{\circ} \mathrm{C}$ and the reduced volume required for the HT, especially as increasing temperatures where the process pressure developed would require thicker wall reactors. 
Table 1. Structural properties of the samples obtained at different hydrothermal treatment times and temperatures.

\begin{tabular}{|c|c|c|c|c|c|c|c|}
\hline Sample & $\begin{array}{l}\text { SBET }^{a} \\
\left(\mathrm{~m}^{2} / \mathrm{g}\right)\end{array}$ & $\begin{array}{c}\mathrm{Vt}^{\mathrm{b}} \\
\left(\mathrm{cm}^{3} / \mathrm{g}\right)\end{array}$ & $\begin{array}{c}\mathrm{Vm}^{\mathrm{c}} \\
\left(\mathrm{cm}^{3} / \mathrm{g}\right)\end{array}$ & $\begin{array}{l}\mathrm{DP} d \\
(\mathrm{~nm})\end{array}$ & $\begin{array}{c}\rho_{\mathrm{a}}^{\mathrm{e}} \\
\left(\mathrm{g} / \mathrm{cm}^{3}\right)\end{array}$ & $a_{0}{ }^{f}(n m)$ & $\operatorname{RER}^{\mathrm{g}}(\%)$ \\
\hline $24 / 80 *$ & 905 & 0.965 & 0.338 & 5.7 & 0.045 & 11.3 & 80 \\
\hline $24 / 80$ & 861 & 0.943 & 0.330 & 5.9 & 0.049 & 11.6 & 40 \\
\hline $24 / 100$ * & 878 & 1.151 & 0.323 & 6.8 & 0.045 & 12.3 & 100 \\
\hline $24 / 100$ & 870 & 1.157 & 0.317 & 7.0 & 0.045 & 12.4 & 47 \\
\hline $24 / 130$ & 613 & 1.214 & 0.179 & 7.4 & 0.046 & 12.4 & 57 \\
\hline $0 / 80$ & 730 & 0.707 & 0.291 & 4.9 & 0.087 & 11.0 & 25 \\
\hline $2 / 80$ & 789 & 0.749 & 0.317 & 4.9 & 0.074 & 11.1 & 26 \\
\hline $6 / 80$ & 833 & 0.827 & 0.335 & 4.9 & 0.054 & 11.3 & 29 \\
\hline $15 / 80$ & 870 & 0.906 & 0.342 & 6.1 & 0.049 & 11.6 & 35 \\
\hline $24 / 80$ & 861 & 0.943 & 0.330 & 5.9 & 0.049 & 11.6 & 40 \\
\hline
\end{tabular}

${ }^{a}$ BET (Brunauer-Emmett-Teller) surface area [30]; ${ }^{\mathrm{b}}$ Total pore volume at $\mathrm{P} / \mathrm{P}_{0}=0.995 ;{ }^{\mathrm{c}}$ Dubinin Micropore volume [31]; ${ }^{\mathrm{d}}$ Pore diameter BJH (Barret-Joyner-Halenda) method applied to the desorption branch; ${ }^{\mathrm{e}}$ Apparent density; ${ }^{\mathrm{f}}$ Length of the hexagonal unit cell; $\mathrm{g}$ Relative energy required; * Synthesis developed without reducing the supernatant liquor before the hydrothermal treatment.

Intensity of the planes (100) and (110) increases with the temperature while in (200) reflection decreases, in good agreement with literature [32]. The shift of the XRD reflections to lower angles at high temperatures, thus increasing the length of the hexagonal unit cell and decreasing the wall thicknesses, was also observed by other authors (i.e., references [25,28,33-35]). The elimination of part of mother liquors in the intermediate stages of the synthesis (during the hydrothermal treatment) have not evidenced significant differences. These results could be an important simplification of the reactors for working in a large scale.

Accordingly to Benamor et al. [36], increasing the time of the hydrothermal treatment results in effects similar to increasing the temperature.

Figure 3 shows the variation of the unit cell parameter with $\mathrm{TH}$ and $\mathrm{tH}$. It is possible to observe a saturating behavior in both cases; thus, from a temperature of $100{ }^{\circ} \mathrm{C}$ and $15 \mathrm{~h}$ of hydrothermal treatment, the observed variation is lower.

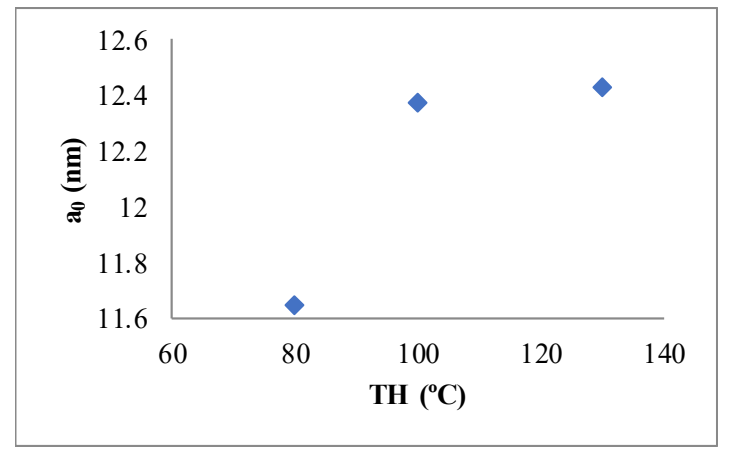

(a)

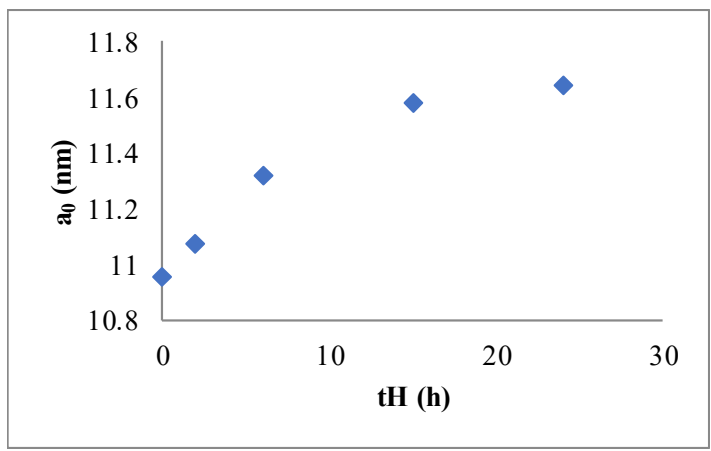

(b)

Figure 3. Evolution of the unit cell parameter with the variables of the study-80, 100, and $130{ }^{\circ} \mathrm{C}$ (a) and $0,2,6,15$, and $24 \mathrm{~h}(\mathbf{b})$.

Figures 4 and 5 show the $77 \mathrm{~K} \mathrm{~N}_{2}$ adsorption isotherms of the different SBA-15 synthesized. Table 1 shows the results obtained for BET surface area, total and micropore volume, as well as the pore diameter obtained from the desorption branch. All isotherms show the typical type IV behavior characteristic of the SBA-15 mesoporous materials. 


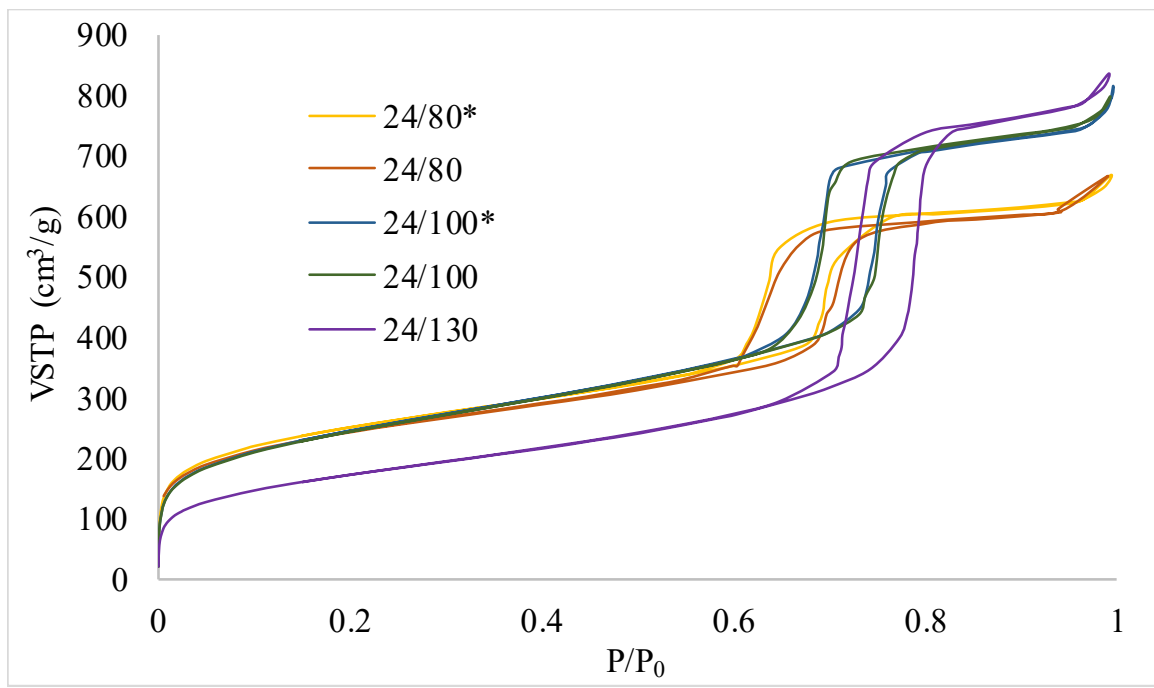

Figure 4. $\mathrm{N}_{2}$ adsorption isotherms corresponding to the samples $24 / 80^{*}, 24 / 80,24 / 100^{*}, 24 / 100$, and 24/130. * Synthesis developed without reducing the supernatant liquor before the hydrothermal treatment.

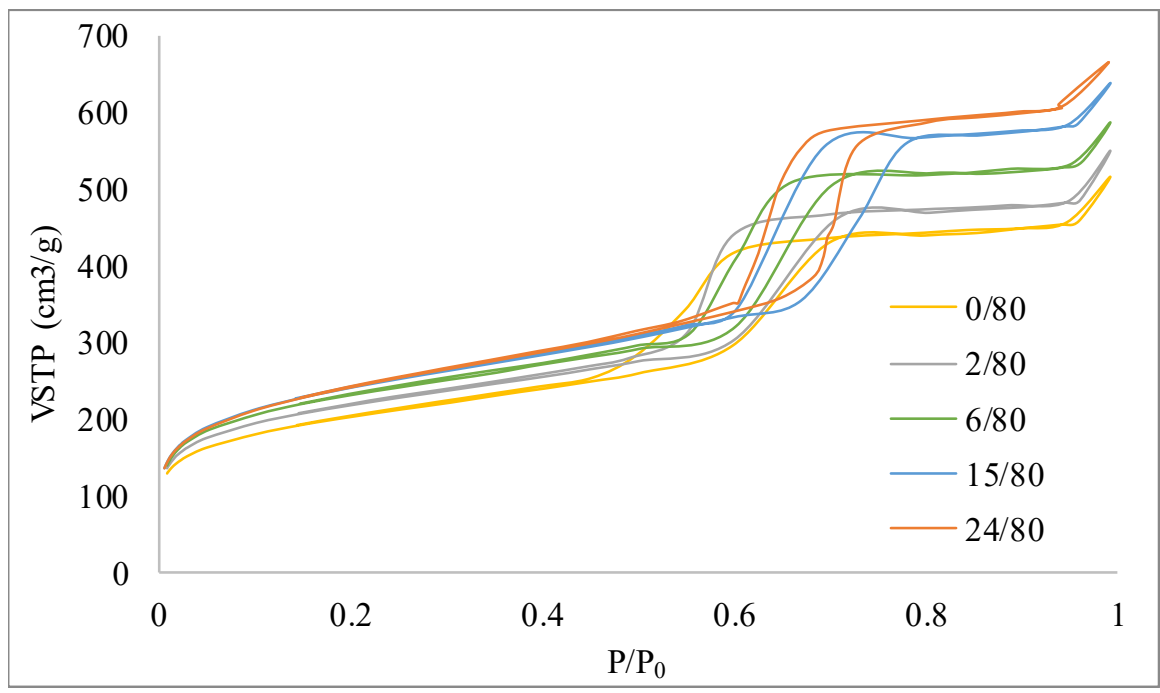

Figure 5. $\mathrm{N}_{2}$ adsorption isotherms corresponding to the samples $0 / 80,2 / 80,6 / 80,15 / 80$, and 24/80.

Considering the influence of the temperature of the hydrothermal treatment, it can be observed that the total pore volume and the pore diameter increase with increasing temperature. On the contrary, the BET surface area and the micropore volume show the opposite tendency. Other authors reported similar behavior [37] that obtained a very similar variation of the textural parameters with a marked decrease of the BET area for the sample synthetized at the highest temperature. Several authors report the increasing temperature increases the mesoporous nature of the SBA-15 materials [26,38], especially at temperatures above $60{ }^{\circ} \mathrm{C}$ [39], and decreases in the microporosity. This process could be due, according to Galarneau et al. [24], to the decrease in the solvent capacity of water with respect to the PEO (poly(ethylene oxide) units of P123 when temperature increases. On the other hand, no significant differences can be associated with the partial removal of the supernatant liquid.

The hydrothermal treatment time also exhibits the expected behavior, widely described (for example) in the references $[14,20,25,40]$. The micro and mesoporosity are markedly increased as a consequence of the consolidation of the structure of the SBA-15 with time. According to Tasfy et al. [41], by increasing the time, the development of the self-assembly process could result in an increase in the total pore volume and a decrease in the volume of micropores. The sample obtained without 
hydrothermal treatment $(0 \mathrm{~h})$ presents the typical structure of these materials, although this structure is much less developed than in a conventional SBA-15.

The apparent density of the samples is presented in Table 1. Neither the temperature nor the amount of reaction medium present during the hydrothermal treatment (study of the partial reduction of supernatant liquor) shows any significant influence on this parameter. Conversely, the time of hydrothermal treatment causes a marked decrease in density, especially at shorter times. After $6 \mathrm{~h}$, the parameter values begin to stabilize, as can be seen in Figure 6.

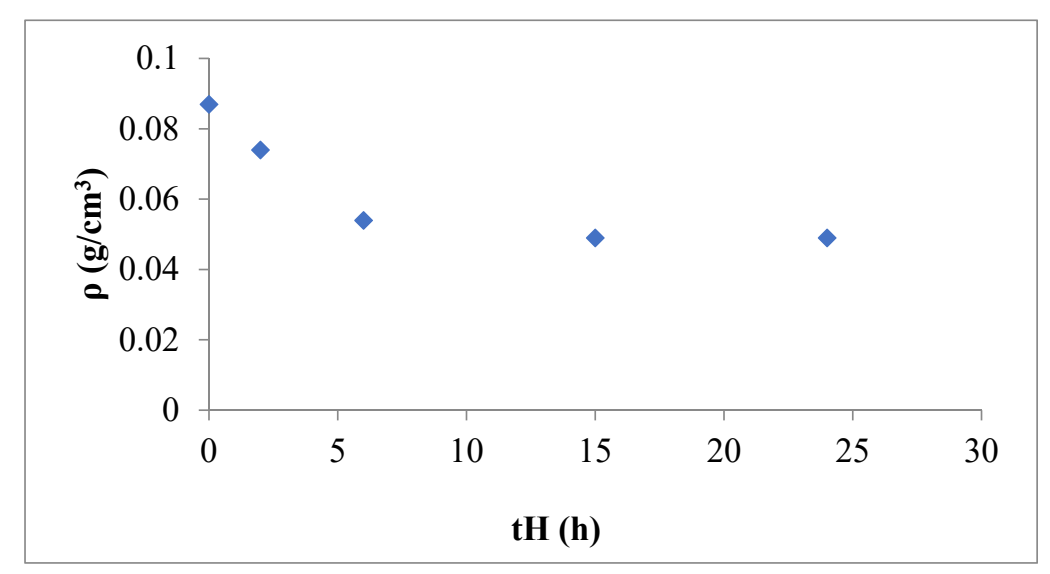

Figure 6. Apparent density vs time of the hydrothermal treatment.

Figure 7 shows these SEM micrographs for the different synthesized materials, all of which have a morphology similar to a fiber with different characteristics. Generally, no significant differences are observed, except for the sample 0/80, which was synthesized without hydrothermal treatment. In this sample, some agglomerates of smaller size appear; these structures are the precursors of the fibers at longer times of hydrothermal treatment. The appearance of fibrous morphology when reaction time increases was also previously observed by Koh et al. [14].

Probably, the differences in apparent density are due to the degree of packing that the material acquires when placed in a container. This fact depends on the density of the particles as well as on their morphology, which affects the way they are packed. The short and less elongated particles of the samples obtained at shorter times of hydrothermal treatment are capable of being packed in a denser way than the fibers of different lengths obtained at longer times, thus yielding higher apparent densities.

It can be concluded that the synthesized materials have developed typical properties of SBA-15 materials, and the evolution of these characteristics is in accordance with the properties described by numerous authors.

\subsection{Smoking Experiment Results}

The main objective of this study is to determine the effect of the variables of synthesis of the SBA-15 and the textural properties developed on the reduction of toxic compounds of tobacco smoke. In a previous work [9], we ran similar smoking experiments using an SBA-15 synthetized under exactly the same conditions as the present sample 24/100, and the results obtained were similar to those obtained in the present work. Nevertheless, no similar studies varying the textural properties of the catalysts have been run to date, and no similar studies have been found in the literature.

Reductions were calculated as the amount of a given compound or family of compounds obtained when smoking the tobacco without a catalyst minus the amount obtained when smoking the corresponding mixture with a catalyst, divided by the amount obtained without a catalyst, expressed as a percentage. Reductions of total particulate matter (TPM), nicotine, carbon dioxide, and carbon monoxide are shown in Table 2. Detailed results of the composition of the gases and TPM collected, 
were expressed in respect of the mass of tobacco smoked. The reductions for the different compounds in the gas and particulate matter are presented in Tables A1 and A2.
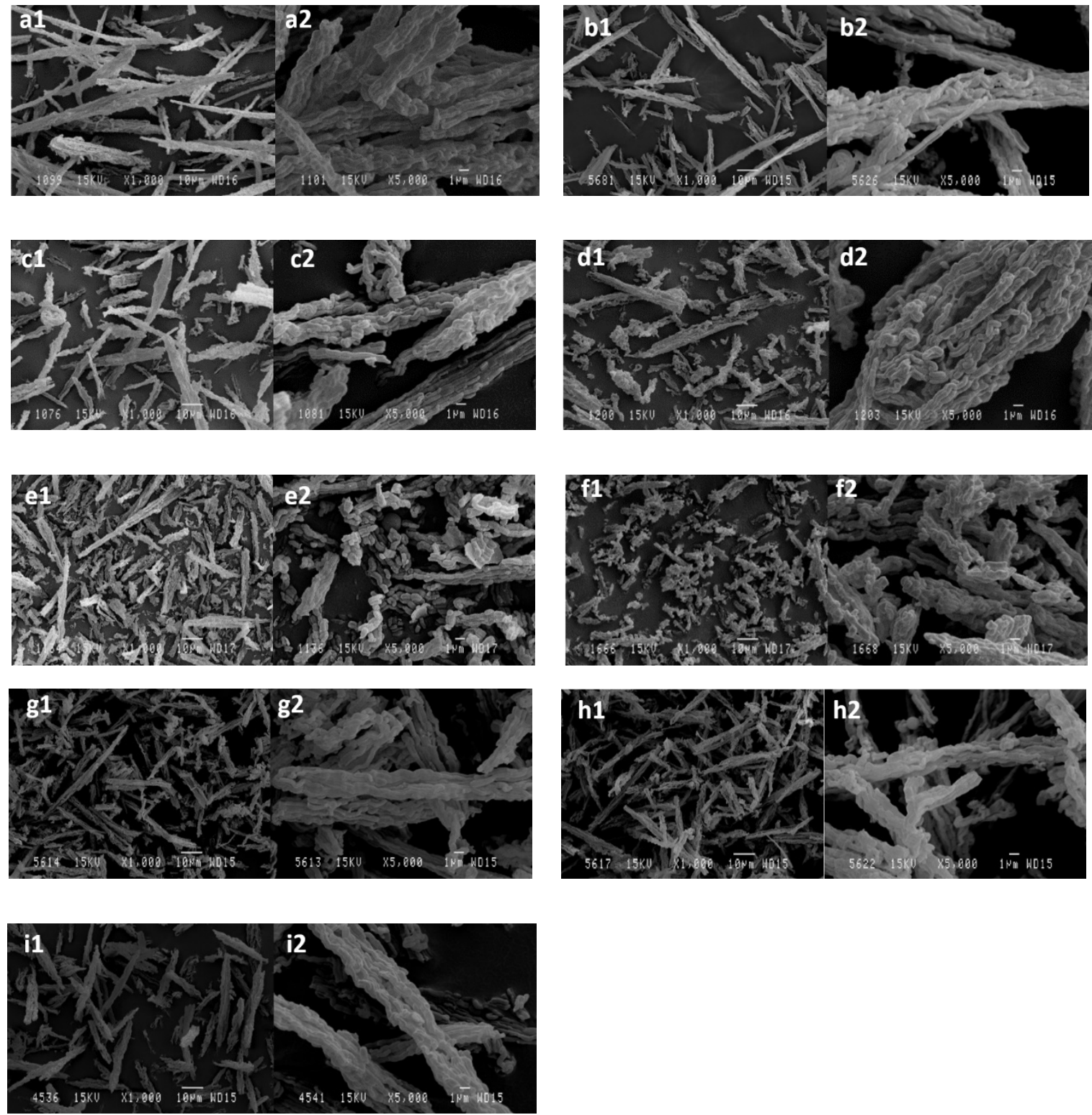

Figure 7. SEM micrographs of the SBA-15 catalyst synthesized: (a) 24/80*, (b) 24/80, (c) 24/100*, (d) 24/100, (e) 24/130, (f) 0/80, (g) 2/80, (h) 6/80, and (i) 15/80, at two different magnifications. * Synthesis developed without reducing the supernatant liquor before the hydrothermal treatment.

Figure 8 presents the results of reductions in TPM, nicotine, and carbon oxides when studying the effect of the temperature of the hydrothermal treatment, eliminating part of the reaction medium present in this step of the synthesis and with the samples obtained following the usual procedure described in the literature (i.e., with all the mother liquor). It can be seen that the effect of removing part of the reaction medium is very small. This low effect had been observed in the textural properties developed by the catalysts. It can therefore be concluded that most of the mother liquor can be eliminated during the hydrothermal treatment, thus obtaining similar results. Therefore, the volume of the required vessels can be reduced accordingly. 
Table 2. Reduction expressed in \% of total particulate matter (TPM), nicotine, $\mathrm{CO}_{2}, \mathrm{CO}$, and gases from smoking experiments to study the effect of the variables on hydrothermal treatment.

\begin{tabular}{cccccc}
\hline Sample & TPM (\%) & Nicotine $(\mathbf{\%})$ & $\mathbf{C O}_{\mathbf{2}} \mathbf{( \% )}$ & $\mathbf{C O}(\mathbf{\%})$ & Gases $(\%)$ \\
\hline $24 / 80 *$ & 65.6 & 63.4 & 22.9 & 28.6 & 22.7 \\
$24 / 80$ & 68.1 & 66.8 & 23.4 & 31.0 & 27.8 \\
$24 / 100 *$ & 65.0 & 60.6 & 34.8 & 37.3 & 33.1 \\
$24 / 100$ & 67.4 & 61.2 & 38.2 & 39.1 & 44.0 \\
$24 / 130$ & 65.6 & 60.3 & 25.6 & 30.0 & 29.9 \\
\hline $0 / 80$ & 36.0 & 28.1 & -0.3 & 2.5 & 10.4 \\
$2 / 80$ & 41.9 & 33.9 & 14.1 & 21.0 & 13.8 \\
$6 / 80$ & 60.9 & 55.0 & 18.1 & 24.3 & 17.7 \\
$15 / 80$ & 74.9 & 66.4 & 29.0 & 34.0 & 23.3 \\
$24 / 80$ & 68.1 & 66.8 & 23.4 & 31.0 & 27.8 \\
\hline
\end{tabular}

* Synthesis developed without reducing the supernatant liquor before the hydrothermal treatment.

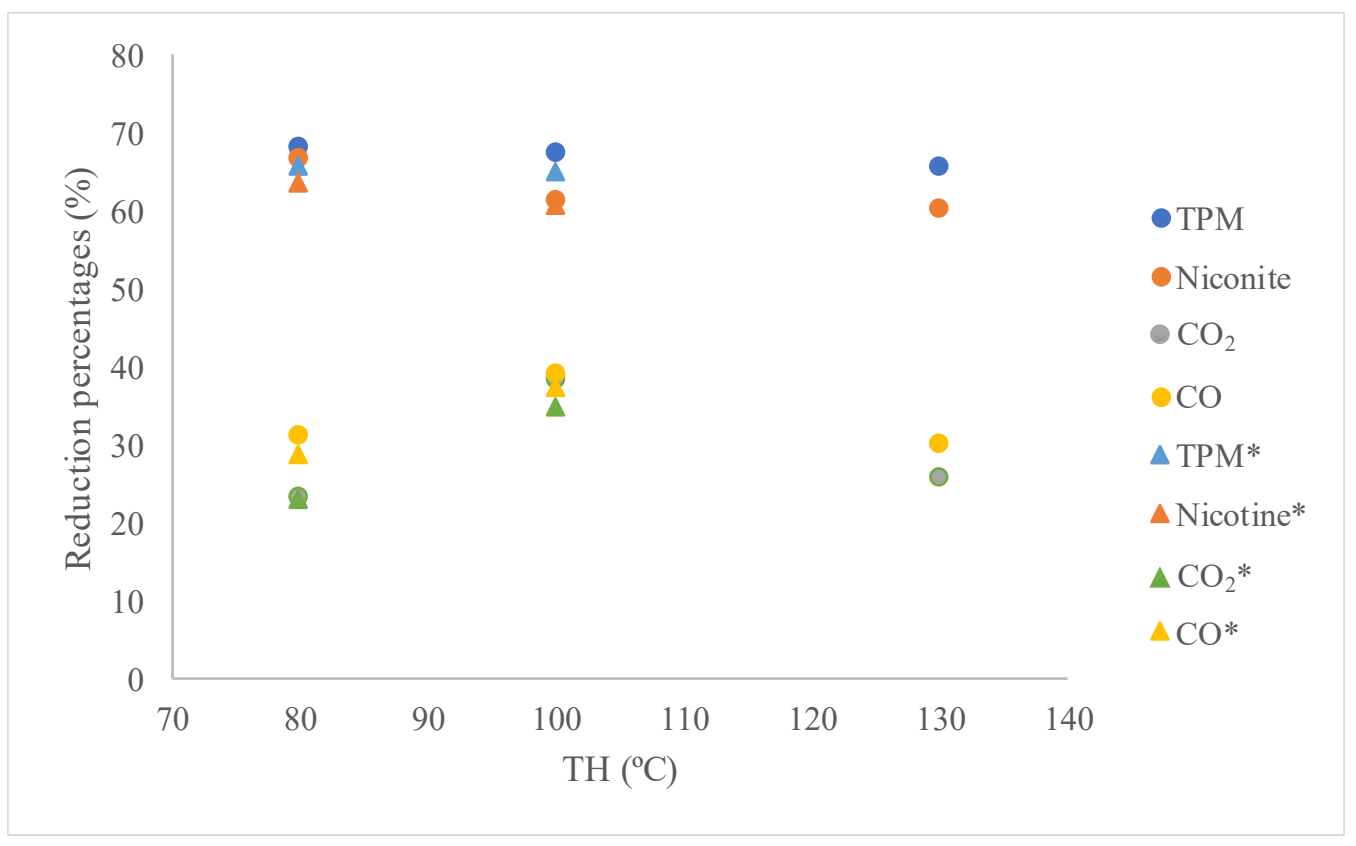

Figure 8. Reduction results of TPM, nicotine, and carbon oxides at different temperatures of hydrothermal treatment. * correspond to samples obtained after eliminating part of the supernatant liquor.

On the other hand, increasing the TH results in a decrease in the reduction ability of nicotine and TPM, while the values for carbon oxides show a maximum at $100^{\circ} \mathrm{C}$. Although the sample synthesized at $130{ }^{\circ} \mathrm{C}$ presented slightly lower results in gases and similar results in TPM, it is possible to affirm that all samples show similar and very large reduction capacity for most compounds.

The results obtained for the different compounds analyzed in the gas fraction are shown in Table A1. These compounds have been grouped into paraffins, olefins, aromatics, aldehydes, and other gases, and the results are shown in Figure 9. In this case, no clear trends are observed, as in the previous compounds. The removal of part of the reaction medium shows very small differences in the case of paraffins and olefins at $80^{\circ} \mathrm{C}$. However, at $100{ }^{\circ} \mathrm{C}$ there is an increase in reductions. Moreover, when part of the mother liquor is eliminated, a maximum can be generally observed in the reductions of the rest of the families. This effect could be related to the decrease in microporosity and with the widening of the mesopores shown by increasing the temperature of the hydrothermal treatment. 


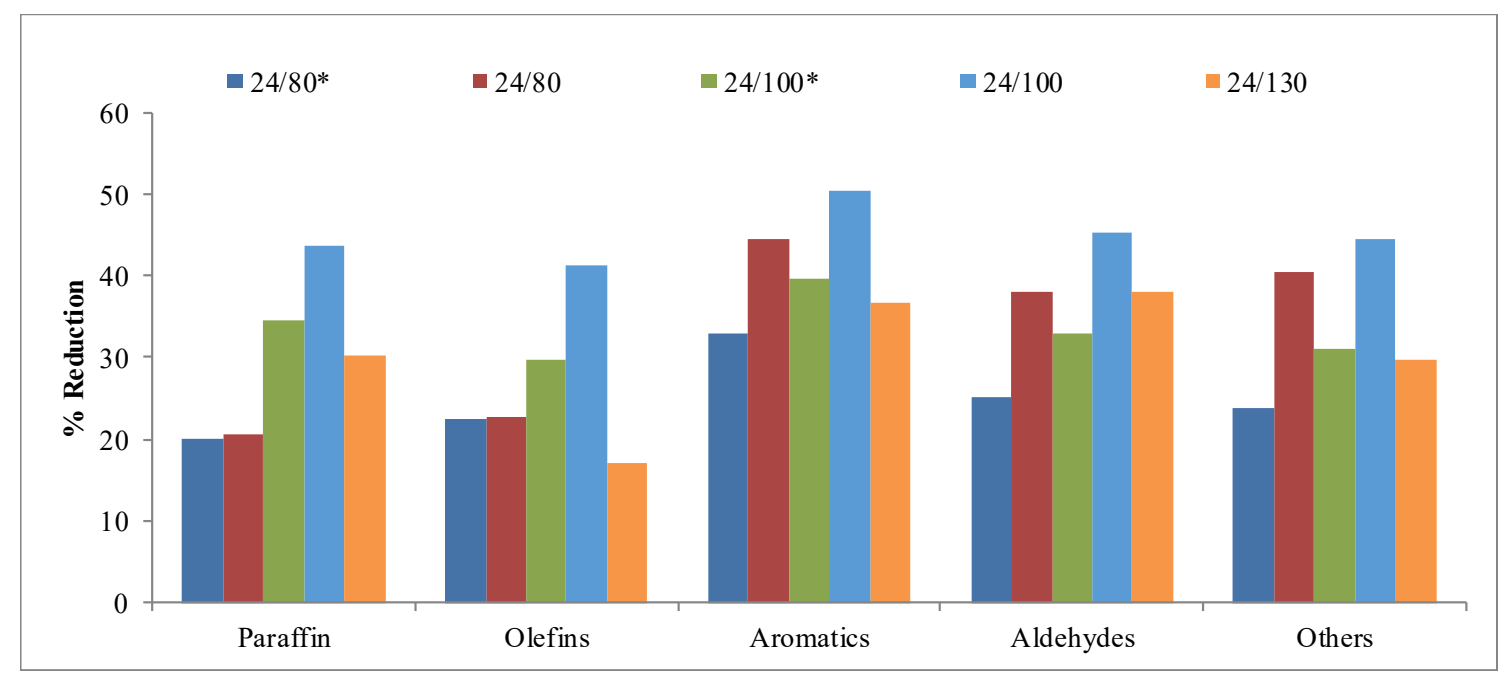

Figure 9. Reduction obtained for the different families of compounds in the gases collected in the study of the hydrothermal treatment temperature. * Synthesis developed without reducing the supernatant liquor before the hydrothermal treatment.

Figure 10 shows the reductions obtained for the different families of compounds considered in the fraction of the total particulate matter-nitrogenated, carbonyl, epoxy, phenolic, aliphatic, etc. In these compounds, a greater effect than in the gas fraction can be observed. In this sense, all the catalysts obtained are very effective in reducing tobacco smoke compounds. In fact, most families show reductions around 70\%; even carbonyls and phenolic present higher values. As in the previous cases, the elimination of part of the reaction medium during the hydrothermal treatment step leads to similar or better results, and except in the epoxy family, where the results at $80^{\circ} \mathrm{C}$ are better than at $100{ }^{\circ} \mathrm{C}$ and $130^{\circ} \mathrm{C}$, it seems that the influence of temperature is not very significant.

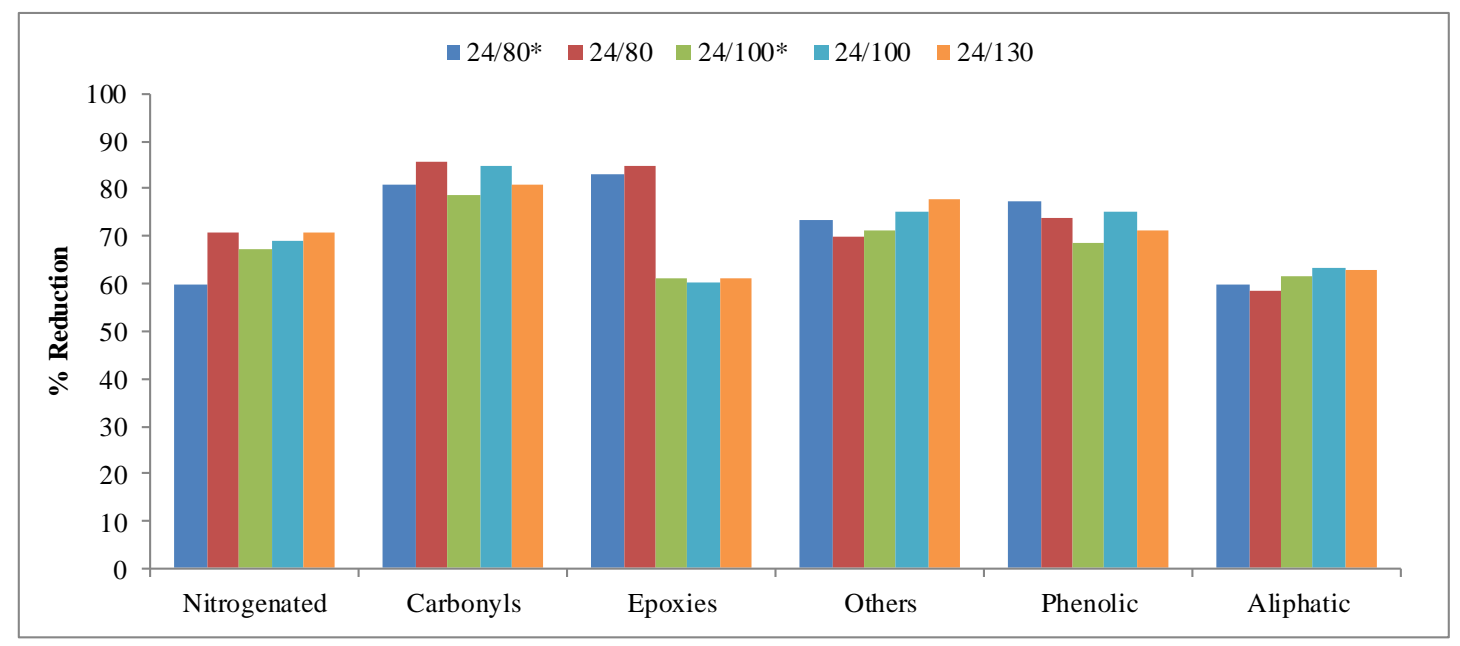

Figure 10. Reduction obtained for the different families of compounds in the total particular matter collected in the study of the hydrothermal treatment temperature. ${ }^{*}$ Synthesis developed without reducing the supernatant liquor before the hydrothermal treatment.

It can be concluded that the SBA-15 synthesized in this study show good behavior as catalysts for reducing the toxicity of tobacco smoke. Furthermore, reducing the amount of mother liquor during the hydrothermal treatment leads to very good results. This would allow for the use of smaller volume equipment, which is especially relevant when considering that such equipment must stand the pressure generated in the process. On the other hand, good results have also been obtained for the proposed 
application at all temperatures studied; therefore, the lowest of these temperatures $\left(80^{\circ} \mathrm{C}\right)$ could be chosen for large-scale manufacturing. Both issues could have important implications for reducing the manufacturing costs of these materials in large-scale processes.

Table 2 also shows the results obtained when studying the time of hydrothermal treatment, maintaining $\mathrm{TH}$ at $80^{\circ} \mathrm{C}$. It is possible to see that this variable has a marked influence on the ability to reduce toxic compounds in tobacco smoke. Increasing tH increases the effect of the catalysts obtained by increasing the reductions of all the compounds or families of compounds considered, and this increase is much more marked during the first $15 \mathrm{~h}$.

Figure 11 (gas fraction) and Figure 12 (TPM) present the reduction results obtained for the different families as a function of $\mathrm{tH}$. It is possible to observe a clear growing trend, both in the gas and TPM fractions, when increasing the time of hydrothermal treatment. However, the results obtained at $15 \mathrm{~h}$ of hydrothermal treatment are very similar to, or even better than, those obtained at $24 \mathrm{~h} \mathrm{tH}$. Therefore, it is feasible to reduce the time of the hydrothermal treatment and still achieve good results for this application. This fact can be, again, very important when considering a large-scale production process.

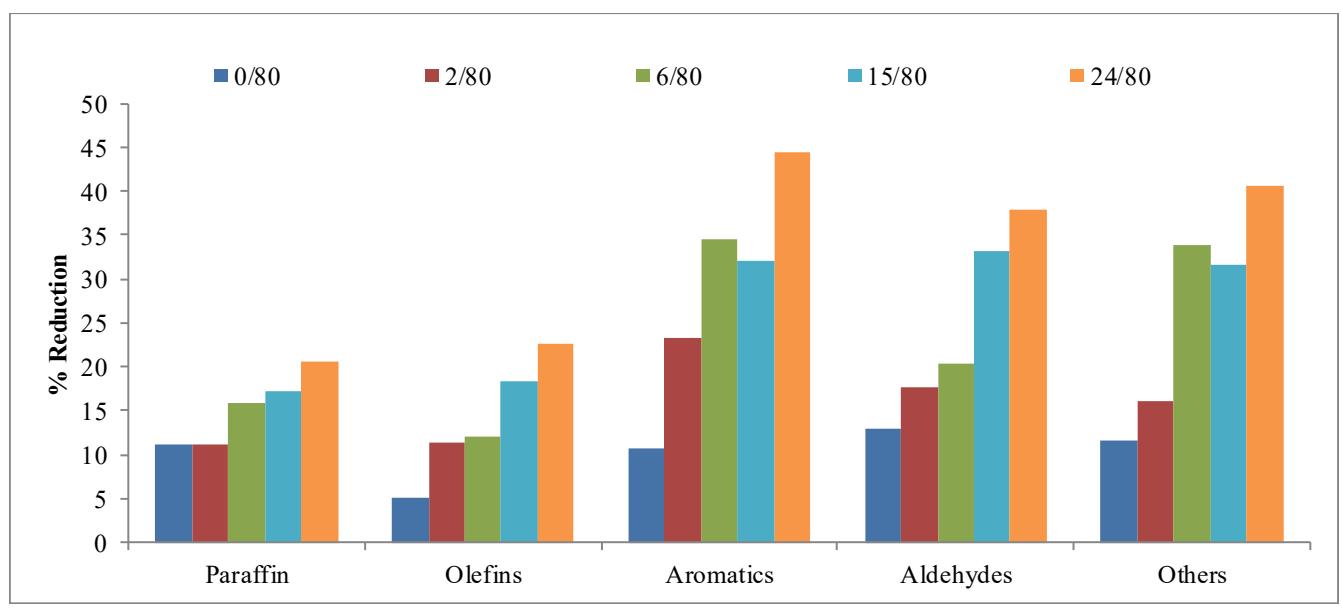

Figure 11. Reduction obtained for the different families of compounds in the gases collected in the study of the hydrothermal treatment time.

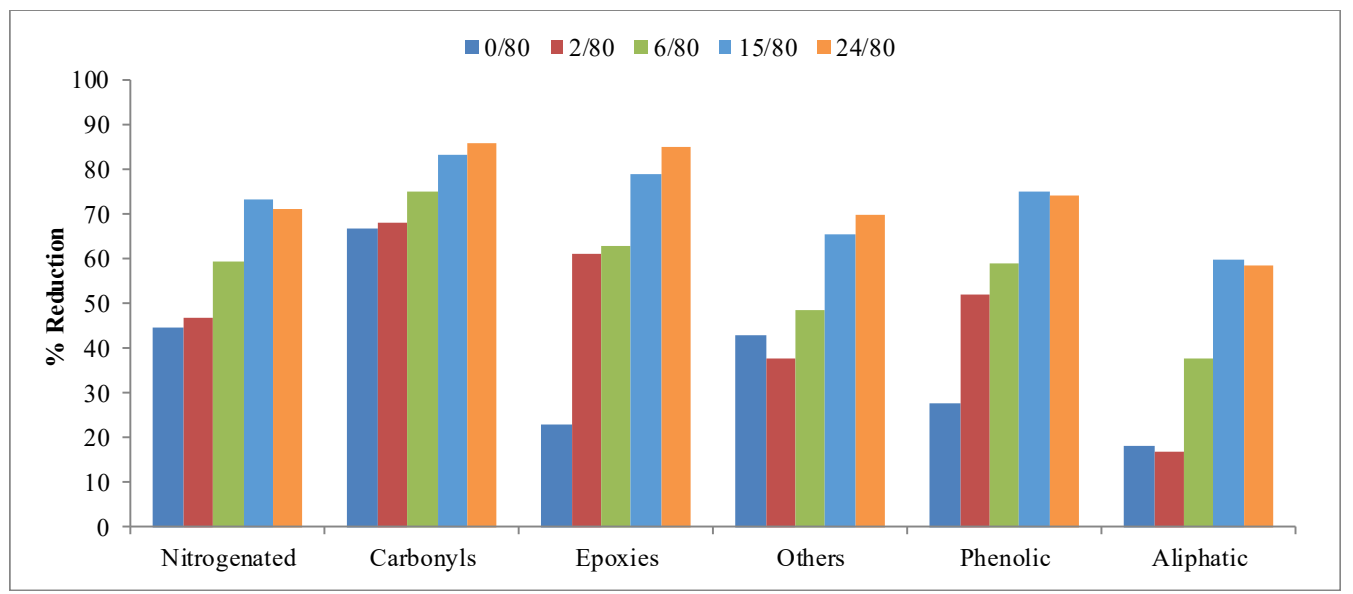

Figure 12. Reduction obtained for the different families of compounds in the total particular matter collected in the study of the hydrothermal treatment time.

The reactions involved during tobacco smoking are very complex [42-45]. The effect of the different catalysts on the products obtained in the smoking process can also be the result of different mechanisms involving adsorption and catalysis, in the primary reactions of the components of the raw material, and for the secondary reactions on the products generated in the primary reactions. All of this 
occurs under dynamic conditions where the temperature, the oxygen concentration, and the flowrate of the circulating gases are not constant. Several authors have studied the effect of zeolites and some mesoporous materials on the different compounds present in tobacco smoke, focusing on the most toxic, such as nitrosamines and PHA, as well as nicotine and certain specific compounds [8,46-48]. The results are a combination of the porous structure of the catalysts used, the conditions present in the smoking experiments, and the nature of the tobacco and the way in which the mixture is prepared.
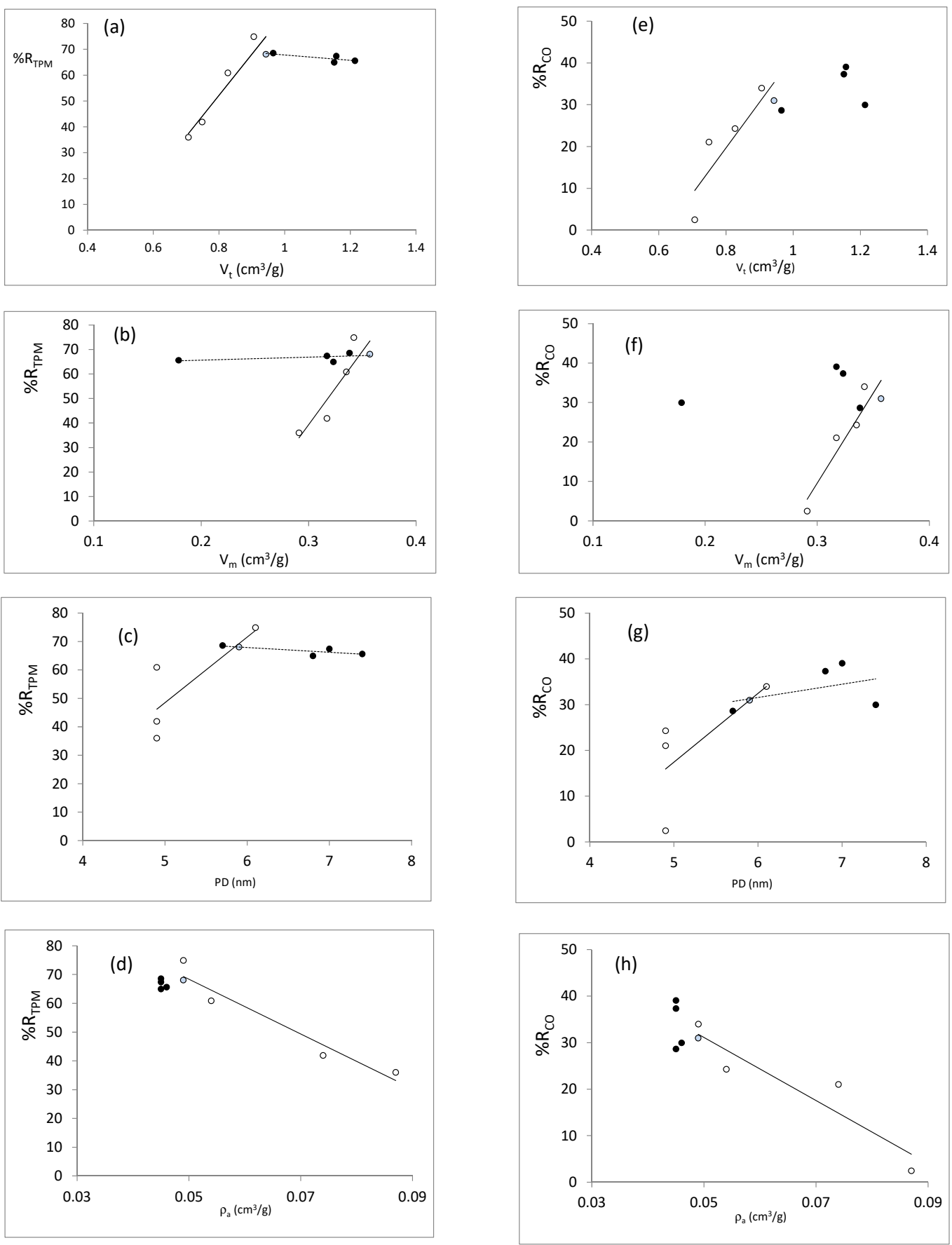

Figure 13. TPM reductions vs structural properties: (a) total pore volume, (b) mesoporous volume, (c) pore diameter and (d) relative density. CO reductions vs structural properties: (e) total pore volume, (f) mesoporous volume, (g) pore diameter, and (h) relative density. Black circles represent the series of temperature, white circles the series of time, and blue circle corresponds to the sample obtained at $24 \mathrm{~h}$ of thermal treatment at $80{ }^{\circ} \mathrm{C}$. 
In order to analyze the effect of the properties developed by the different catalysts synthetized on their behavior in smoking experiments, we have plotted in Figure 13a-h the reduction in TPM (nicotine follows a similar trend) vs the textural parameters selected and the apparent density of the SBA-15. Figure $13 \mathrm{e}-\mathrm{h}$ represents the reduction in $\mathrm{CO}$. We have considered the reductions in TPM, nicotine (graphs not shown because are similar to those of TPM), and carbon monoxide because they are the three parameters contemplated until now in tobacco regulations and can be considered representative of the trends observed for most compounds. The trend observed when plotting the reductions vs surface area (not shown) are very similar to those obtained when plotting vs micropore volume. In these graphs, the blue circle corresponds to the sample synthesized during $24 \mathrm{~h}$ of hydrothermal treatment at $80^{\circ} \mathrm{C}$; thus, it is common to both series, i.e., $\mathrm{TH}$ and reduction supernatant liquid (black circles) and $\mathrm{tH}$ (white circles). It can be seen that the reductions in TPM (and nicotine) and CO provided by the catalysts are strongly correlated with the different structural parameters in the series where the time of hydrothermal treatment was varied. Positive correlations are obtained, as could be expected, with the total pore volume, micropore volume (surface area), and pore diameter. However, a negative correlation with the apparent density is observed, probably as a result of better tobacco catalyst contact when decreasing the apparent density. When analyzing the temperature series (black circles), the results observed for the TPM reductions seem to be independent of the structural parameters, and all samples exhibit similar behavior.

\section{Materials and Methods}

\subsection{Synthesis of $S B A-15$}

SBA-15 materials were prepared according to the synthesis described by Zhao et al. [28], varying the time and temperature of the hydrothermal treatment. To obtain $1 \mathrm{~g}$ of material, $1.75 \mathrm{~g}$ Pluronic P123, a triblock poly(ethylene oxide)-poly(propylene oxide)-poly(ethylene oxide) copolymer (from Sigma Aldrich, Saint Louis, MO, U.S.), were dissolved in $56.32 \mathrm{~mL}$ of $\mathrm{H}_{2} \mathrm{O}$ and $9.31 \mathrm{~mL}$ of $\mathrm{HCl} 11.32 \mathrm{M}$ from Merck (for at least $1 \mathrm{~h}$, Madrid, Spain). Then, $3.67 \mathrm{~g}$ of tetraethyl orthosilicate, TEOS (from Sigma-Aldrich, Saint Louis, MO, U.S.) was added, and the mixture was stirred at $40^{\circ} \mathrm{C}$ for $24 \mathrm{~h}$ (this part of the synthesis is what we refer to as the first step). The resulting suspensions were treated at different temperatures $(\mathrm{TH})$ and times $(\mathrm{tH})$ under static conditions in tapered bottles. This second part is the hydrothermal treatment $(\mathrm{H})$. The solid resulting from this step was collected by filtration and dried at $100{ }^{\circ} \mathrm{C}$ for two hours. Finally, the product was calcined at $550{ }^{\circ} \mathrm{C}$ for $5 \mathrm{~h}$, sieved and tested.

As mentioned above, in this work two variables that can affect the synthesis process were studied, temperature $(\mathrm{TH})$ and time $(\mathrm{tH})$ of the hydrothermal process. For the study of temperature, a time of $24 \mathrm{~h}$ was fixed and temperatures of 80,100 , and $130^{\circ} \mathrm{C}$ were selected. Samples are named by two figures separated by a slash; the first one refers to the $\mathrm{tH}$ in hours, whereas the second refers to the $\mathrm{TH}$ in ${ }^{\circ} \mathrm{C}$. Thus, the samples prepared in the first series are $24 / 80^{*}$ and $24 / 100^{*}$. Moreover, to reduce the volume of the synthesis media at high temperatures during the hydrothermal treatment what would contribute to simplifying the equipment required in industrial applications, another series of synthesis was carried out, removing the $2 / 3$ of the suspending solution. Samples are identified as $24 / 80,24 / 100$, and 24/130, similarly to the previous samples but removing the asterisk, since all other samples in this study were prepared by reducing the volume of the reaction medium to $1 / 3$ of the original one. A third series was prepared to determine the effect of the time of hydrothermal treatment, and $0-, 2,6,15$, and $24 \mathrm{~h}$ were chosen, maintaining the temperature at $80^{\circ} \mathrm{C}$ and removing the excess of suspending medium (time and temperature of the first step were always $24 \mathrm{~h}$ and $40^{\circ} \mathrm{C}$, respectively). Thus, the samples are named as 0/80, 2/80, 6/80, and 15/80.

\subsection{Characterization}

Textural properties and morphology of the obtained materials were characterized as follows: 
X-ray diffraction (XRD) patterns were analyzed with a Bruker D8-Advance with X-ray diffraction equipment KRISTALLOFLEX K 760-80F (Bruker, Madrid, Spain), equipped with an X-ray tube with a $\mathrm{Cu}$ anode. The samples were radiated using $\mathrm{CuK} \alpha\left(\lambda_{\mathrm{K} \alpha}=0.15406 \mathrm{~nm}\right)$, between $0^{\circ}$ and $5^{\circ}(2 \theta)$.

The porous texture of SBA-15 was determined with an automatic AUTOSORB-6 from Quantachrome (Anton-Paar, Madrid, Spain). $\mathrm{N}_{2}$ adsorption isotherms at $77 \mathrm{~K}$ were determined. Surface areas were calculated according to the BET method, micropore volume was determined according to the Dubinin-Raduskevich method, and the total volume was obtained from the $\mathrm{N}_{2}$ adsorbed at $\mathrm{P} / \mathrm{P}_{0}=0.965$. The pore size distributions were determined by applying the $\mathrm{BJH}$ model to the desorption branch of the isotherm [49].

Micrographs of the samples were obtained using a scanning electron microscope (SEM) JEOL JSM-840 (Tokyo, Japan) operating at $15 \mathrm{kV}$. Before the analysis, samples were gold covered by using a metallizer (Au)/evaporator (C) BALZERS, SCD 004 model (Balzers, Liechtenstein).

The apparent density of these powder materials is a very relevant property in the application we are studying since it may be related, in addition to the morphology of the particles, to the way the catalyst particles contact the tobacco strands. To determine such apparent density, the volume occupied by a given weight of the corresponding material was determined. The packing degree is very important in determining this property; thus, samples were handled in exactly the same conditions. This parameter was determined by filling a recipient of known volume with the sample and weighing the amount required, after shanking four times under the same condition and compacting to the mark. The reproducibility of this procedure was greater than $95 \%$ when the tests were repeated in triplicate.

\subsection{Smoking Analysis}

\subsubsection{Cigarette Preparation}

3R4F reference tobacco from the Center for Tobacco Reference of Kentucky University (Lexington, KY, USA) was selected for the smoking experiments. Details of this procedure can be found elsewhere $[9,50]$. Typically, to ensure the homogeneity between experiments, 120 cigarettes with around $0.78 \mathrm{mg}$ of tobacco were emptied and the tobacco was conditioned for at least $48 \mathrm{~h}$ at $22{ }^{\circ} \mathrm{C}$ and $60 \%$ of relative humidity based on the ISO 3402 standard [51]. Tobacco-additive mixtures were prepared manually. Tobacco was wet with around $0.1 \mathrm{~g}$ of ethanol per cigarette to favor the contact of the catalyst over the tobacco. Then, the corresponding amount of around 4.8 weight $\%$ of the total tobacco-SBA-15 mixture was added and thoroughly mixed. The emptied tubes of the 3R4F cigarettes were re-filled with the tobacco catalyst mixture (around $0.78 \mathrm{~g}$ of tobacco $+0.033 \mathrm{~g}$ of SBA-15). In order to have a reference for the behavior of this tobacco without a catalyst, emptied tubes were refilled with 3R4F tobacco (similarly wet with the same amount of ethanol). In this way, both cigarettes, i.e., those with a catalyst and those without a catalyst, were manipulated in similar ways.

For the investigation, 10 cigarettes of each sample, including the reference, were smoked in each smoking experiment, after being conditioned for at least, $48 \mathrm{~h}$ under the same conditions mentioned previously.

\subsubsection{Smoking Experiments}

The smoking regime was designed according to the international standard ISO 3308 [52], i.e., $2 \mathrm{~s}$ puffs of $35 \mathrm{~mL}$ every $60 \mathrm{~s}$. The smoking machine employed has a capacity of five cigarettes per test to be smoked with a pressure of aspiration never higher than $1.5 \mathrm{kPa}$.

During the smoking experiment, the mainstream smoke passes through the cigarette, then through two traps and finally reaches the Tedlar gas collection bag (Sigma Aldrich-Merck, Darmstadt, Germany). The first trap is a common filter of $8 \mathrm{~mm}$ of cellulose acetate, and the second is made of glass microfiber (filter Whatman trap of $47 \mathrm{~mm}$, Fisher Scientific, Madrid, Spain). In this sense, two fractions corresponding to tobacco smoke were considered: the total particulate matter (TPM) retained on both traps and the gaseous portion collected in the Tedlar bag. 


\subsubsection{Analysis of the Particulate Matter}

To determine the total particulate matter (TPM), secondary filters and the Whatman microfilter were weighed together according to the ISO 4387 [53], and the contents were calculated considering the amount of tobacco smoked. Results are reported as $\mathrm{mg}$ compound i/g tobacco smoked. For each sample, filters were weighed before and after the experiment, and the tobacco smoked was determined as the difference between the initial amount of tobacco and the tobacco in the cigarette butt after the essay. For the determination of the quantity of each compound on secondary filters and the Whatman microfilter, they were extracted using three successive additions of $20 \mathrm{~mL}$ of 2-propanol from Fisher Chemical (Madrid, Spain). The resulting extracts were placed together and analyzed by GC/MS using an Agilent $6890 \mathrm{~N}$ gas chromatographer coupled to a mass spectrometer detector (Agilent 5973N, Agilent Technologies, Barcelona, Spain) with an electron impact (EI) ionization source and a quadrupole analyzer. In the assays, $1 \mu \mathrm{L}$ of sample was injected using helium as the carrier gas. The injector temperature was $250^{\circ} \mathrm{C}$ and the GC oven program started at $40{ }^{\circ} \mathrm{C}$ for $5 \mathrm{~min}$, continued with a ramp of $12{ }^{\circ} \mathrm{C} / \mathrm{min}$ until $320^{\circ} \mathrm{C}$, and ended holding this temperature for $25 \mathrm{~min}$. An HP5-MS chromatographic column was used.

\subsubsection{Analysis of the Vapor Phase}

The gas fraction was analyzed in two separate runs. In the first one, an Agilent 6890N GC gas chromatographer (Agilent Technologies, Barcelona, Spain) with a G2747A methanizer was employed to determine $\mathrm{CO}$ and $\mathrm{CO}_{2}$. Helium was used as the carrier gas (flow rate $40 \mathrm{~mL} / \mathrm{min}$ ) using a packet column Porapak (Porapak Q 80-100 mesh, Agilent Technologies, Barcelona, Spain) at $60^{\circ} \mathrm{C} .100 \mu \mathrm{L}$ of gas sample was injected at $150^{\circ} \mathrm{C}$, the temperature of the catalyst was $375^{\circ} \mathrm{C}$, and that of the flame ionizer detector (FID), $300^{\circ} \mathrm{C}$. In the second one, other volatile compounds were quantified by GC/FID using an Agilent $6890 \mathrm{~N}$ chromatographer (Agilent Technologies, Barcelona, Spain) with a GS-GASPRO (Agilent Technologies, Barcelona, Spain) column. In this case, the volume of sample injected was $150 \mu \mathrm{L}$ in the injector at $150{ }^{\circ} \mathrm{C}$. The GC oven program started at a temperature of $35^{\circ} \mathrm{C}$ for $5 \mathrm{~min}$, continued with the first ramp of $5{ }^{\circ} \mathrm{C} / \mathrm{min}$ until $100{ }^{\circ} \mathrm{C}$, followed by the second ramp of $15^{\circ} \mathrm{C} / \mathrm{min}$ until $200^{\circ} \mathrm{C}$, and ended by holding this temperature for $10 \mathrm{~min}$. The detector temperature was $210^{\circ} \mathrm{C}$.

All SBA-15 samples were synthetized by duplication. Catalyst characterization and smoking runs were also replicated. The results presented are the average of the two corresponding runs, and differences observed between replicates were always within the typical values of the corresponding techniques used. Larger deviations were observed, as expected, in the smoking experiments. Nevertheless, they were lower than $15 \%$ for the majority compounds and fractions reported.

\section{Conclusions}

This study shows the effect of temperature and time on the hydrothermal treatment of the SBA-15 catalyst synthesis on the developed structure and textural properties and on the reduction of tobacco toxic compounds in the smoking process.

The evolution of the XRD patterns show an increase in the unit cell parameter with time and temperature of the hydrothermal treatment. Likewise, the increase in temperature results in an increase in the volume of pores, a decrease in the contribution of micropores, and an increase of that of mesopores and their widening. Increasing the time of the hydrothermal treatment monotonically increases the micro and mesoporosity and increases the diameter of the pores. These results agree with those described by other authors when studying the influence of these variables.

The catalysts synthesized at three temperatures showed high levels of reduction of toxic compounds with similar results for the total particulate matter. However, for the volatile compounds, a slight increase in the reduction for the SBA- 15 synthesized at $100{ }^{\circ} \mathrm{C}$ with respect to the other samples was observed. On the contrary, the variation of the time in the hydrothermal treatment has a marked effect on the ability of reducing tars, carbon monoxide, nicotine and most of the toxic substances. 
In this case, high levels of reduction were reached after $6 \mathrm{~h}$ of hydrothermal treatment at $80{ }^{\circ} \mathrm{C}$, which even improved during the $15 \mathrm{~h}$ and $24 \mathrm{~h}$ processes. This behavior could be observed for total particulate matter and volatile compounds. Synthesis 15/80 yield the best results with $75 \%$ TPM, $66 \%$ nicotine, and $29 \%$ CO reductions, in addition to large reductions in all families of compounds considered, with around $1 / 3$ of the energy requirements respect to the synthesis $24 / 100^{*}$ and providing similar results.

Samples prepared after reducing the supernatant liquor before to the hydrothermal treatment showed no significant differences compared to samples synthesized by the conventional method but considerable energy saving potential. All this information can be very important for reducing costs of an eventual SBA-15 production process on an industrial scale. Finally, one aspect that we would like to highlight is that the use of these materials may help in matching the recent suggestion of the FDA (U.S. Food and Drug Administration) [54] to reduce nicotine levels in cigarettes to $0.5 \mathrm{mg} / \mathrm{g}$ of tobacco filler in order to reach the objective of minimizing levels of addiction.

Author Contributions: Conceptualization, A.M.; Data curation, N.J.-S. and A.M.; Formal analysis, N.J.-S. and I.M.-C.; Investigation, N.J.-S. and J.A.; Methodology, N.J.-S. and A.M.; Project administration, A.M.; Resources, A.M.; Supervision, A.M.; Validation, N.J.-S. and A.M.; Visualization, N.J.-S. and A.M.; Writing-original draft, N.J.-S.; Writing - review and editing, N.J.-S., M.B., and A.M. All authors have read and agreed to the published version of the manuscript.

Acknowledgments: The authors wish to thank the Spanish Government, project TQ2015-70726-P (MINECO/ FEDER), and the Valencian Conselleria d'Educació, Investigació, Cultura I Esport, project PROMETEO/2016/056 and IDIFEDER 2018/009 for financial support.

Conflicts of Interest: The authors declare no conflict of interest. 


\section{Appendix A}

Table A1. Reduction percentages (\%) of the different compounds identified in the gaseous fraction collected for the tobacco-catalyst mixtures respect to the 3R4F tobacco reference for the studies of time, temperature, and reduction of the supernatant liquor in the hydrothermal treatment. * Synthesis developed without reducing the supernatant liquor before the hydrothermal treatment.

\begin{tabular}{|c|c|c|c|c|c|c|c|c|c|c|c|}
\hline Compound & Family & $24 / 80 *$ & $24 / 80$ & $24 / 100 *$ & $24 / 100$ & $24 / 130$ & $0 / 80$ & $2 / 80$ & $6 / 80$ & $15 / 80$ & $24 / 80$ \\
\hline Methane & Paraffins & 20.5 & 21.2 & 33.9 & 43.0 & 32.1 & 16.4 & 13.0 & 17.3 & 18.3 & 21.2 \\
\hline Ethane & Paraffins & 25.5 & 22.4 & 34.1 & 43.9 & 32.7 & 11.5 & 12.4 & 15.8 & 18.8 & 22.4 \\
\hline Ethylene & Olefins & 22.0 & 20.7 & 31.6 & 40.3 & 22.0 & 3.1 & 8.9 & 16.1 & 20.8 & 20.7 \\
\hline Ethyne & Others & 9.8 & 6.7 & 27.6 & 41.1 & -7.7 & -77.9 & -22.5 & 17.2 & -29.4 & 6.7 \\
\hline Propane & Paraffins & 28.1 & 18.1 & 34.4 & 43.5 & 32.7 & 12.1 & 6.7 & 12.5 & 11.5 & 18.1 \\
\hline Propene & Olefins & 26.3 & 25.0 & 34.0 & 43.2 & 26.6 & 8.9 & 12.1 & 15.2 & 30.6 & 25.0 \\
\hline Iso-butane & Parafins & -13.4 & -9.2 & 56.2 & 57.2 & -58.4 & -16.0 & -22.3 & 2.7 & -17.6 & -9.2 \\
\hline Chloromethane & Others & 31.6 & 31.6 & 35.7 & 41.3 & 33.5 & 7.4 & 12.9 & 18.3 & 7.0 & 31.6 \\
\hline Butane & Paraffins & 31.2 & 9.4 & 42.2 & 49.1 & 33.5 & 10.3 & -8.1 & 9.6 & 16.5 & 9.4 \\
\hline 1-Butene & Olefins & 29.3 & 28.1 & 36.5 & 44.2 & 31.1 & 10.3 & 14.0 & 15.7 & 17.6 & 28.1 \\
\hline 1,2-Propadiene & Olefins & 27.4 & 28.6 & 37.3 & 39.7 & 21.0 & -9.3 & 22.1 & 29.8 & 4.6 & 28.6 \\
\hline 1,3-Butadiene & Olefins & 28.8 & 26.6 & 32.0 & 43.6 & 27.5 & 5.9 & 14.7 & 13.6 & 22.4 & 26.6 \\
\hline Isobutene & Olefins & 23.7 & 25.6 & 33.2 & 40.6 & 20.3 & -6.7 & 10.4 & 6.1 & 15.8 & 25.6 \\
\hline cis-2-Butene & Olefins & 27.9 & 26.8 & 33.7 & 42.9 & 24.5 & -0.4 & 11.3 & 14.0 & 9.1 & 26.8 \\
\hline Pentane & Paraffins & 23.4 & 21.3 & 33.1 & 40.4 & 32.0 & 16.2 & 13.3 & -0.8 & 20.2 & 21.3 \\
\hline Methanethiol & Others & -17.3 & 34.5 & 17.1 & 29.9 & 24.6 & 6.3 & 13.2 & 19.9 & 11.2 & 34.5 \\
\hline Hydrogen cyanide & Others & 26.1 & 22.0 & 32.0 & 41.8 & 31.5 & -1.3 & 9.0 & -0.1 & -7.1 & 22.0 \\
\hline 1-Pentene & Olefins & 27.4 & 25.0 & 33.5 & 39.5 & 25.6 & 6.3 & 12.4 & 12.9 & -0.6 & 25.0 \\
\hline Furan & Aromatics & 30.7 & 37.5 & 38.7 & 49.5 & 18.7 & 13.0 & 15.0 & 21.0 & 12.3 & 37.5 \\
\hline Isoprene & Olefins & 14.7 & 19.1 & 18.8 & 39.1 & -7.1 & 6.4 & 11.9 & 4.3 & 9.1 & 19.1 \\
\hline Hexane & Paraffins & 22.9 & 0.8 & 14.9 & 54.4 & -43.9 & -28.1 & 9.3 & -21.3 & -10.7 & 0.8 \\
\hline 1-Hexene & Olefins & 23.1 & 25.0 & 35.1 & 45.1 & 30.3 & -5.1 & 6.0 & 7.8 & 0.4 & 25.0 \\
\hline Benzene & Aromatics & 33.1 & 44.3 & 37.6 & 47.0 & 37.7 & 10.2 & 27.6 & 37.2 & 29.8 & 44.3 \\
\hline Acetaldehyde & Aldehydes & 26.5 & 35.6 & 38.7 & 49.9 & 42.9 & 22.6 & 19.5 & 18.4 & 36.4 & 35.6 \\
\hline Acrolein & Aldehydes & -36.0 & 4.0 & -32.2 & -6.9 & -7.1 & -68.6 & -37.3 & -29.7 & -23.3 & 4.0 \\
\hline Propionaldehyde & Aldehydes & 29.6 & 44.9 & 32.1 & 45.0 & 35.9 & 11.1 & 22.1 & 29.9 & 35.8 & 44.9 \\
\hline Acetonitrile & Others & 37.6 & 71.5 & 31.6 & 57.4 & 56.4 & 55.4 & 36.4 & 61.3 & 87.0 & 71.5 \\
\hline Toluene & Aromatics & 30.3 & 48.0 & 52.5 & 65.3 & 52.1 & 20.0 & 9.2 & 27.1 & 57.1 & 48.0 \\
\hline 2,5-Dimethylfuran & Aromatics & 37.1 & 48.2 & 43.4 & 63.5 & 25.5 & 2.0 & 14.7 & 35.5 & 39.2 & 48.2 \\
\hline Crotonaldehyde & Aldehydes & 23.8 & 33.6 & 26.5 & 36.7 & 52.0 & -232.7 & -47.3 & -74.8 & -31.4 & 33.6 \\
\hline Isobutyraldehyde & Aldehydes & 32.8 & 25.3 & 44.6 & 54.0 & 44.3 & 7.7 & -7.5 & -24.4 & 15.8 & 25.3 \\
\hline
\end{tabular}


Table A2. Reduction percentages (\%) of the different compounds identified in the collected fraction of the total particulate matter for the tobacco-catalyst mixtures respect to the $3 \mathrm{R} 4 \mathrm{~F}$ tobacco reference for the studies of time, temperature, and reduction of the supernatant liquor in the hydrothermal treatment. * Synthesis developed without reducing the supernatant liquor before the hydrothermal treatment.

\begin{tabular}{|c|c|c|c|c|c|c|c|c|c|c|c|}
\hline Compound & Family & $24 / 80 *$ & $24 / 80$ & $24 / 100 *$ & $24 / 100$ & $24 / 130$ & $0 / 80$ & $2 / 80$ & $6 / 80$ & $15 / 80$ & $24 / 80$ \\
\hline 2-(1-methylethoxy)-Ethanol & Epoxies & 82.6 & 82.5 & 61.4 & 46.9 & 76.5 & 100.0 & 53.1 & 64.0 & 73.0 & 82.5 \\
\hline 1-(acetyloxy)-2-Propanone & Carbonyls & 100.0 & 100.0 & 100.0 & 100.0 & 100.0 & 24.3 & 100.0 & 100.0 & 100.0 & 100.0 \\
\hline Styrene & Aromatics & 100.0 & 100.0 & 100.0 & 100.0 & 100.0 & 100.0 & 100.0 & 100.0 & 100.0 & 100.0 \\
\hline 2-methyl-2-Cyclopenten-1-one & Carbonyls & 100.0 & 100.0 & 100.0 & 100.0 & 100.0 & 100.0 & 100.0 & 100.0 & 100.0 & 100.0 \\
\hline 2,5-Dimethyl-2-cyclopentenone & Carbonyls & 100.0 & 100.0 & 100.0 & 100.0 & 100.0 & 18.2 & 100.0 & 100.0 & 100.0 & 100.0 \\
\hline Phenol & Phenolics & 100.0 & 92.7 & 58.7 & 75.2 & 86.3 & 45.2 & 79.7 & 87.5 & 85.3 & 92.7 \\
\hline 2-hydroxy-3-methyl-2-Cyclopenten-1-one & Carbonyls & 94.0 & 95.3 & 92.1 & 93.4 & 87.8 & 100.0 & 86.2 & 92.3 & 98.7 & 95.3 \\
\hline Limonene & Others & 57.6 & 66.3 & 58.1 & 69.6 & 79.6 & 32.9 & 35.7 & 48.1 & 64.4 & 66.3 \\
\hline 2,3-Dimethyl-2-cyclopenten-1-one & Carbonyls & 100.0 & 100.0 & 100.0 & 100.0 & 100.0 & 100.0 & 100.0 & 100.0 & 100.0 & 100.0 \\
\hline o-Cresol & Phenolics & 100.0 & 88.3 & 70.3 & 82.9 & 85.9 & 64.8 & 64.9 & 77.3 & 82.6 & 88.3 \\
\hline p-Cresol & Phenolics & 100.0 & 89.9 & 71.1 & 76.8 & 86.1 & 47.5 & 77.1 & 85.5 & 92.1 & 89.9 \\
\hline 2-methoxy-Phenol & Phenolics & 100.0 & 97.6 & 50.8 & 100.0 & 100.0 & 80.9 & 83.4 & 84.5 & 91.9 & 97.6 \\
\hline 2-Propanamine & Nitrogenated & 100.0 & 100.0 & 68.6 & 100.0 & 100.0 & 67.8 & 100.0 & 100.0 & 100.0 & 100.0 \\
\hline 3-Ethyl-2-hydroxy-2-cyclopenten-1-one & Carbonyls & 100.0 & 94.4 & 81.8 & 100.0 & 100.0 & 100.0 & 82.5 & 88.5 & 92.8 & 94.4 \\
\hline 2,3-Dihydro-3,5-dihydroxy-6-methyl-4H-pyran-4-one & Carbonyls & 77.1 & 81.3 & 72.7 & 74.8 & 70.3 & 68.4 & 54.9 & 70.0 & 79.3 & 81.3 \\
\hline 2,4-dimethyl-Phenol & Phenolics & 100.0 & 93.1 & 100.0 & 100.0 & 100.0 & 32.0 & 71.8 & 77.4 & 90.1 & 93.1 \\
\hline 4-ethyl-Phenol & Phenolics & 100.0 & 86.0 & 100.0 & 100.0 & 100.0 & 59.7 & 61.2 & 66.6 & 80.4 & 86.0 \\
\hline Naphthalene & Others & 100.0 & 100.0 & 100.0 & 100.0 & 100.0 & 100.0 & 100.0 & 100.0 & 100.0 & 100.0 \\
\hline 1-(3-methylphenyl)-Ethanone & Carbonyls & 100.0 & 100.0 & 100.0 & 100.0 & 100.0 & 100.0 & 100.0 & 100.0 & 100.0 & 100.0 \\
\hline p-cresol 2 methoxy & Phenolics & 100.0 & 100.0 & 100.0 & 100.0 & 100.0 & 100.0 & 100.0 & 100.0 & 100.0 & 100.0 \\
\hline 2,3-Dihydro-benzofuran & Epoxies & 83.2 & 85.5 & 60.9 & 66.1 & 54.7 & -38.5 & 62.9 & 62.2 & 80.2 & 85.5 \\
\hline Hydroquinone & Phenolics & 16.6 & 41.3 & 26.9 & 37.0 & 12.7 & -4.2 & 60.7 & 34.4 & 50.9 & 41.3 \\
\hline 1H-Indole & Nitrogenated & 41.1 & 46.7 & 21.6 & 20.7 & 15.0 & 68.0 & 50.3 & 69.3 & 85.4 & 46.7 \\
\hline 4-vinyl-2-methoxy-phenol & Phenolics & 78.6 & 82.6 & 61.3 & 77.2 & 79.3 & 21.0 & 69.4 & 76.5 & 86.9 & 82.6 \\
\hline 3-methyl-1H-Indole & Nitrogenated & 88.1 & 82.7 & 79.3 & 75.2 & 79.3 & 15.6 & 60.4 & 62.7 & 74.4 & 82.7 \\
\hline Myosmine & Nitrogenated & 81.7 & 75.3 & 66.5 & 73.4 & 80.2 & 20.3 & 32.0 & 56.5 & 72.5 & 75.3 \\
\hline 2-methoxy-4-(2-propenyl)-Phenol & Phenolics & 76.5 & 92.4 & 71.1 & 84.0 & 76.4 & 64.1 & 56.2 & 100.0 & 100.0 & 92.4 \\
\hline Nicotyrine & Nitrogenated & 93.4 & 93.6 & 89.3 & 86.7 & 92.7 & 67.3 & 84.8 & 90.7 & 92.9 & 93.6 \\
\hline Norsolanadiona & Carbonyls & 75.0 & 69.5 & 70.1 & 72.9 & 82.3 & 28.9 & 44.0 & 51.4 & 61.7 & 69.5 \\
\hline $2,3^{\prime}$-Bipyridine & Nitrogenated & 79.6 & 70.2 & 73.2 & 77.5 & 80.1 & 45.9 & 25.6 & 29.8 & 62.6 & 70.2 \\
\hline
\end{tabular}


Table A2. Cont.

\begin{tabular}{|c|c|c|c|c|c|c|c|c|c|c|c|}
\hline Compound & Family & $24 / 80 *$ & $24 / 80$ & $24 / 100$ * & $24 / 100$ & $24 / 130$ & $0 / 80$ & $2 / 80$ & $6 / 80$ & $15 / 80$ & $24 / 80$ \\
\hline Megastigmatrienone & Carbonyls & 64.0 & 65.3 & 61.2 & 64.0 & 63.2 & 20.1 & 58.1 & 60.7 & 100.0 & 65.3 \\
\hline N-propyl- nornicotine & Nitrogenated & 100.0 & 71.9 & 62.4 & 65.6 & 61.6 & -121.6 & 1.4 & 15.2 & 37.0 & 71.9 \\
\hline Cotinine & Nitrogenated & 64.0 & 64.5 & 66.8 & 66.1 & 54.3 & 50.8 & 31.2 & 41.6 & 60.0 & 64.5 \\
\hline 5-Tetradecene & Aliphatics & 62.8 & 71.9 & 78.7 & 82.5 & 71.1 & 38.5 & 38.9 & 58.6 & 73.2 & 71.9 \\
\hline $\mathrm{N}(\mathrm{b})$-formylnornicotine & Nitrogenated & -352.1 & -29.2 & -37.2 & -25.9 & -6.9 & 1.4 & 22.8 & 45.6 & 56.4 & -29.2 \\
\hline Neophytadiene & Aliphatics & 49.8 & 57.8 & 43.6 & 48.4 & 57.5 & 3.1 & 23.1 & 42.4 & 60.6 & 57.8 \\
\hline Farnesol & Others & 58.3 & 51.6 & 50.6 & 51.1 & 49.6 & 10.6 & 12.8 & 25.6 & 51.9 & 51.6 \\
\hline Ethyl ester hexadecanoic acid & Carbonyls & 59.4 & 78.3 & 75.5 & 80.9 & 60.6 & 50.2 & 56.6 & 62.9 & 71.8 & 78.3 \\
\hline 2,6,10,15,19,23-hexamethyl-2,6,10,14,18,22-Tetracosahexaene & Aliphatics & 21.7 & 40.9 & 47.3 & 25.3 & 35.9 & 22.8 & 15.9 & 21.8 & 36.3 & 40.9 \\
\hline Heptacosane & Aliphatics & 61.3 & 54.2 & 71.9 & 65.9 & 64.4 & 89.1 & 3.7 & 31.8 & 56.1 & 54.2 \\
\hline Triacontane & Aliphatics & 74.3 & 56.1 & 76.1 & 83.8 & 75.2 & 86.5 & -1.7 & 17.4 & 53.1 & 56.1 \\
\hline Octadecane & Aliphatics & 77.2 & 62.1 & 79.0 & 82.4 & 71.1 & -13.8 & 11.0 & 34.4 & 63.2 & 62.1 \\
\hline Tocopherol & Phenolics & 83.3 & 66.4 & 82.4 & 81.5 & 77.2 & 33.1 & 10.1 & 35.3 & 68.0 & 66.4 \\
\hline
\end{tabular}




\section{References}

1. Wynder, E.L. Tobacco as a Cause of Lung Cancer: Some Reflections. Am. J. Epidemiol. 1997, 146, $687-694$. [CrossRef] [PubMed]

2. Squier, C.A. Smokeless Tobacco and Oral Cancer: A Cause for Concern? CA Cancer J. Clin. 1984, 34, $242-247$. [CrossRef] [PubMed]

3. Wald, N.J.; Nanchahal, K.; Thompson, S.G.; Cuckle, H.S. Does breathing other people's tobacco smoke cause lung cancer? Br. Med. J. 1986, 293, 1217-1222. [CrossRef]

4. Gómez Raposo, C.; de Castro Carpeño, J.; González Barón, M. Factores etiológicos del cáncer de pulmón: Fumador activo, fumador pasivo, carcinógenos medioambientales y factores genéticos. Med. Clin. 2007, 128, 390-396. [CrossRef]

5. Wolfenden, L.; Nathan, N.K.; Sutherland, R.; Yoong, S.L.; Hodder, R.K.; Wyse, R.J.; Delaney, T.; Grady, A.; Fielding, A.; Tzelepis, F.; et al. Strategies for enhancing the implementation of school-based policies or practices targeting risk factors for chronic disease. Cochrane Database Syst. Rev. 2017, 11. [CrossRef] [PubMed]

6. Ngo, A.; Cheng, K.-W.; Shang, C.; Huang, J.; Chaloupka, F. Global Evidence on the Association between Cigarette Graphic Warning Labels and Cigarette Smoking Prevalence and Consumption. Int. J. Environ. Res. Public Health 2018, 15, 421. [CrossRef] [PubMed]

7. Lidón-Moyano, C.; Fu, M.; Ballbe, M.; Martín-Sánchez, J.C.; Matilla-Santander, N.; Martinez, C.; Fernandez, E.; Martínez-Sánchez, J.M. Impact of the Spanish smoking laws on tobacco consumption and secondhand smoke exposure: A longitudinal population study. Addict. Behav. 2017, 75, 30-35. [CrossRef]

8. Meier, W.M.; Siegmann, K. Significant reduction of carcinogenic compounds in tobacco smoke by the use of zeolite catalysts. Microporous Mesoporous Mater. 1999, 33, 307-310. [CrossRef]

9. Marcilla, A.; Beltrán, M.I.; Gómez-Siurana, A.; Martínez, I.; Berenguer, D. Effect of the concentration of siliceous materials added to tobacco cigarettes on the composition of the smoke generated during smoking. Ind. Eng. Chem. Res. 2015, 54, 1916-1929. [CrossRef]

10. Shi, C.L.; Li, S.H.; Sun, X.D.; Wang, Z.P.; Wang, Y.Z.; Xiong, J.W.; Gu, W.B.; Wang, W.M.; Yao, H.M.; Wang, Y.; et al. New activated carbon sorbent with the zeolite-like selectivity to capture tobacco-specific nitrosamines in solution. Chem. Eng. J. 2018, 339, 170-179. [CrossRef]

11. Marcilla, A.; Gómez-Siurana, A.; Berenguer, D.; Martínez-Castellanos, I.; Beltrán, M.I. Reduction of tobacco smoke components yields by zeolites and synthesized Al-MCM-41. Microporous Mesoporous Mater. 2012, 161, 14-24. [CrossRef]

12. Marcilla, A.; Gómez-Siurana, A.; Berenguer, D.; Martínez-Castellanos, I.; Beltrán, M.I. Reduction of tobacco smoke components yield in commercial cigarette brands by addition of HUSY, NaY and Al-MCM-41 to the cigarette rod. Toxicol. Rep. 2015, 2, 152-164. [CrossRef] [PubMed]

13. Wu, Z.Y.; Wang, H.J.; Ma, L.L.; Xue, J.; Zhu, J.H. Eliminating carcinogens in environment: Degradation of volatile nitrosamines by Zeolites Y and ZSM-5. Microporous Mesoporous Mater. 2008, 109, 436-444. [CrossRef]

14. Koh, M.H.; Azaman, S.H.; Hameed, B.H.; Din, A.M. Surface morphology and physicochemical properties of ordered mesoporous silica SBA-15 synthesized at low temperature. IOP Conf. Ser. Mater. Sci. Eng. 2017, 206, 012056. [CrossRef]

15. Alfredsson, V.; Wennerström, H. The Dynamic Association Processes Leading from a Silica Precursor to a Mesoporous SBA-15 Material. Acc. Chem. Res. 2015, 48, 1891-1900. [CrossRef] [PubMed]

16. Bhange, P.; Bhange, D.S.; Pradhan, S.; Ramaswamy, V. Direct synthesis of well-ordered mesoporous Al-SBA-15 and its correlation with the catalytic activity. Appl. Catal. A Gen. 2011, 400, 176-184. [CrossRef]

17. Long, H.; Wang, W.; Yang, W.; Wang, Y.; Ru, H. Facile and controllable preparation of different SBA-15 platelets and their regulated drug release behaviours. Microporous Mesoporous Mater. 2018, 263, $34-41$. [CrossRef]

18. Thielemann, J.P.; Girgsdies, F.; Schlögl, R.; Hess, C. Pore structure and surface area of silica SBA-15: Influence of washing and scale-up. Beilstein J. Nanotechnol. 2011, 2, 110-118. [CrossRef]

19. Chen, S.-Y.; Chen, Y.-T.; Lee, J.-J.; Cheng, S. Tuning pore diameter of platelet SBA-15 materials with short mesochannels for enzyme adsorption. J. Mater. Chem. 2011, 21, 5693. [CrossRef]

20. Jaroniec, M.; Kruk, M.; Ko, C.H.; Ryoo, R. Characterization of the Porous Structure of SBA-15. Chem. Mater. 2000, 12, 1961-1968. 
21. Yilmaz, M.S.; Piskin, S. The removal of template from SBA-15 samples synthesized from different silica sources. J. Therm. Anal. Calorim. 2015, 121, 1255-1262. [CrossRef]

22. Kleitz, F.; Schmidt, W.; Schüth, F. Calcination behavior of different surfactant-templated mesostructured silica materials. Microporous Mesoporous Mater. 2003, 65, 1-29. [CrossRef]

23. Bérubé, F.; Kaliaguine, S. Calcination and thermal degradation mechanisms of triblock copolymer template in SBA-15 materials. Microporous Mesoporous Mater. 2008, 115, 469-479. [CrossRef]

24. Galarneau, A.; Cambon, H.; di Renzo, F.; Ryoo, R.; Choi, M.; Fajula, F. Microporosity and connections between pores in SBA-15 mesostructured silicas as a function of the temperature of synthesis. New J. Chem. 2003, 27, 73-79. [CrossRef]

25. Fulvio, P.F.; Pikus, S.; Jaroniec, M. Tailoring properties of SBA-15 materials by controlling conditions of hydrothermal synthesis. J. Mater. Chem. 2005, 15, 5049. [CrossRef]

26. Johansson, E.M. Controlling the Pore Size and Morphology of Mesoporous Silica; Linköping University Electronic Press: Linköping, Sweden, 2010.

27. Imperor-Clerc, M.; Davidson, P.; Davidson, A. Existence of a Microporous Corona around the Mesopores of Silica-Based SBA-15 Materials Templated by Triblock Copolymers. Am. Chem. Soc. 2000, 122, 11925-11933. [CrossRef]

28. Zhao, D.; Huo, Q.; Feng, J.; Chmelka, B.F.; Stucky, G.D. Nonionic Triblock and Star Diblock Copolymer and Oligomeric Surfactant Syntheses of Highly Ordered, Hydrothermally Stable, Mesoporous Silica Structures. J. Am. Chem. Soc. 1998, 120, 6024-6036. [CrossRef]

29. Klimova, T.; Esquivel, A.; Reyes, J.; Rubio, M.; Bokhimi, X.; Aracil, J. Factorial design for the evaluation of the influence of synthesis parameters upon the textural and structural properties of SBA-15 ordered materials. Microporous Mesoporous Mater. 2006, 93, 331-343. [CrossRef]

30. Brunauer, S.; Emmett, P.H.; Teller, E. Adsorption of Gases in Multimolecular Layers. J. Am. Chem. Soc. 1938, 60, 309-319. [CrossRef]

31. Dubinin, M.M.; Zhukovskaia, E.G. Adsorption properties of carbon adsorbents Communication 2. Adsorption properties of active carbons with respect to benzene and nitrogen vapors. Bull. Acad. Sci. USSR Div. Chem. Sci. 1958, 7, 519-528. [CrossRef]

32. Vinu, A.; Murugesan, V.; Böhlmann, W.; Hartmann, M. An Optimized Procedure for the Synthesis of AlSBA-15 with Large Pore Diameter and High Aluminum Content. J. Phys. Chem. B 2004, 103, 11496-11505. [CrossRef]

33. Guillet-Nicolas, R.; Bérubé, F.; Thommes, M.; Janicke, M.T.; Kleitz, F. Selectively tuned pore condensation and hysteresis behavior in mesoporous SBA-15 silica: Correlating material synthesis to advanced gas adsorption analysis. J. Phys. Chem. C 2017, 121, 24505-24526. [CrossRef]

34. Brodie-Linder, N.; Dosseh, G.; Alba-Simonesco, C.; Audonnet, F.; Impéror-Clerc, M. SBA-15 synthesis: Are there lasting effects of temperature change within the first 10 min of TEOS polymerization? Mater. Chem. Phys. 2008, 108, 73-81. [CrossRef]

35. Bera, B.; Das, N. Synthesis of high surface area mesoporous silica SBA-15 for hydrogen storage application. Int. J. Appl. Ceram. Technol. 2019, 16, 294-303. [CrossRef]

36. Benamor, T.; Vidal, L.; Lebeau, B.; Marichal, C. Influence of synthesis parameters on the physico-chemical characteristics of SBA-15 type ordered mesoporous silica. Microporous Mesoporous Mater. 2012, 153, 100-114. [CrossRef]

37. Zhang, F.; Yan, Y.; Yang, H.; Meng, Y.; Yu, C.; Tu, B.; Zhao, D. Understanding effect of wall structure on the hydrothermal stability of mesostructured silica SBA-15. J. Phys. Chem. B 2005, 109, 8723-8732. [CrossRef]

38. Ruthstein, S.; Frydman, V.; Kababya, S.; Landau, M.; Goldfarb, D. Study of the Formation of the Mesoporous Material SBA-15 by EPR Spectroscopy. Phys. Chem. B 2003, 107, 1739-1748. [CrossRef]

39. Galarneau, A.; Cambon, H.; di Renzo, F.; Fajula, F. True Microporosity and Surface Area of Mesoporous SBA-15 Silicas as a Function of Synthesis Temperature. Langmuir 2001, 17, 8328-8335. [CrossRef]

40. Fulvio, P.F.; Pikus, S.; Jaroniec, M. Short-time synthesis of SBA-15 using various silica sources. J. Colloid Interface Sci. 2005, 287, 717-720. [CrossRef]

41. Tasfy, S.F.H.; Zabidi, N.A.M.; Subbarao, D.; Shaharun, M.S. Effects of Synthesis Conditions on the Textural and Morphological Properties of Mesoporous Silica (SBA-15). Appl. Mech. Mater. 2014, 446, 201-205. [CrossRef] 
42. Torikai, K.; Yoshida, S.; Takahashi, H. Effects of temperature, atmosphere and $\mathrm{pH}$ on the generation of smoke compounds during tobacco pyrolysis. Food Chem. Toxicol. 2004, 42, 1409-1417. [CrossRef] [PubMed]

43. Várhegyi, G.; Czégény, Z.; Jakab, E.; McAdam, K.; Liu, C. Tobacco pyrolysis. Kinetic evaluation of thermogravimetric-mass spectrometric experiments. J. Anal. Appl. Pyrolysis 2009, 86, 310-322. [CrossRef]

44. Polat, S.; Apaydin-Varol, E.; Pütün, A.E. Thermal decomposition behavior of tobacco stem Part II: Kinetic analysis. Energy Sources Part A Recover. Util. Environ. Eff. 2016, 38, 3073-3080. [CrossRef]

45. Collard, F.X.; Blin, J. A review on pyrolysis of biomass constituents: Mechanisms and composition of the products obtained from the conversion of cellulose, hemicelluloses and lignin. Renew. Sustain. Energy Rev. 2014, 38, 594-608. [CrossRef]

46. Sun, X.D.; Li, S.H.; Wang, L.J.; Gu, W.B.; Shi, C.L.; Dong, X.Y.M.; Wang, Y.Z.; Wang, W.M.; Yang, Z.Y.; Wang, Y.; et al. Impact of proton: Capturing tobacco specific N-nitrosamines (TSNA) with HZSM-5 zeolite. Chem. Eng. J. 2017, 323, 180-190. [CrossRef]

47. Gao, L.; Cao, Y.; Zhou, S.L.; Zhuang, T.T.; Wang, Y.; Zhu, J.H. Eliminating carcinogenic pollutants in environment: Reducing the tobacco specific nitrosamines level of smoke by zeolite-like calcosilicate. J. Hazard. Mater. 2009, 169, 1034-1039. [CrossRef]

48. Adnadjevic, B.; Nikolic, M.; Jovanovic, J. Effects Associated with the Structure of Adsorbents on the Degrees to Which Nicotine, Tar and CO are Reduced in Tobacco Smoke; Nova Science Publishers, Inc.: Hauppauge, NY, USA, 2012; pp. 229-246.

49. Barrett, E.P.; Joyner, L.G.; Halenda, P.P. The Determination of Pore Volume and Area Distributions in Porous Substances. I. Computations from Nitrogen Isotherms. J. Am. Chem. Soc. 1951, 73, 373-380. [CrossRef]

50. Marcilla, A.; Beltran, M.I.; Gómez-Siurana, A.; Berenguer, D.; Martínez-Castellanos, I. Comparison between the mainstream smoke of eleven RYO tobacco brands and the reference tobacco 3R4F. Toxicol. Rep. 2014, 1, 122-136. [CrossRef]

51. ISO 3402:1999. Tobacco and Tobacco Products-Atmosphere for Conditioning and Testing; ISO: Geneva, Switzerland, $1999 ;$ p. 9.

52. ISO 3308:2000. Routine Analytical Cigarette-Smoking Machine_Definitions and Standard Conditions; ISO: Geneva, Switzerland, 2000.

53. ISO 4387:2008. Tobacco, Tobacco Products and Related Equipment; ISO: Geneva, Switzerland, 2008.

54. Food and Drug Administration, HHS. Tobacco Product Standard for Nicotine Level of Combusted Cigarettes. Federal Register, 16 March 2018; 11818-11843.

(C) 2020 by the authors. Licensee MDPI, Basel, Switzerland. This article is an open access article distributed under the terms and conditions of the Creative Commons Attribution (CC BY) license (http://creativecommons.org/licenses/by/4.0/). 